\title{
Exosomal miR-940 maintains SRC-mediated oncogenic activity in cancer cells: a possible role for exosomal disposal of tumor suppressor miRNAs
}

\author{
Mohammed H. Rashed ${ }^{1,4}$, Pinar Kanlikilicer ${ }^{1,2}$, Cristian Rodriguez-Aguayo ${ }^{1,2}$, Martin \\ Pichler $^{7}$, Recep Bayraktar ${ }^{1}$, Emine Bayraktar ${ }^{1}$, Cristina Ivan ${ }^{1,2}$, Justyna Filant ${ }^{3}$, \\ Andreia Silva ${ }^{5,6}$, Burcu Aslan ${ }^{1,2}$, Merve Denizli ${ }^{1}$, Rahul Mitra ${ }^{2}$, Bulent Ozpolat ${ }^{1,2}$, \\ George A. Calin ${ }^{1,2}$, Anil K. Sood ${ }^{2,3}$, Mohamed F. Abd-Ellah ${ }^{4}$, Gouda K. Helal ${ }^{4}$, Gabriel \\ Lopez Berestein ${ }^{1,2}$

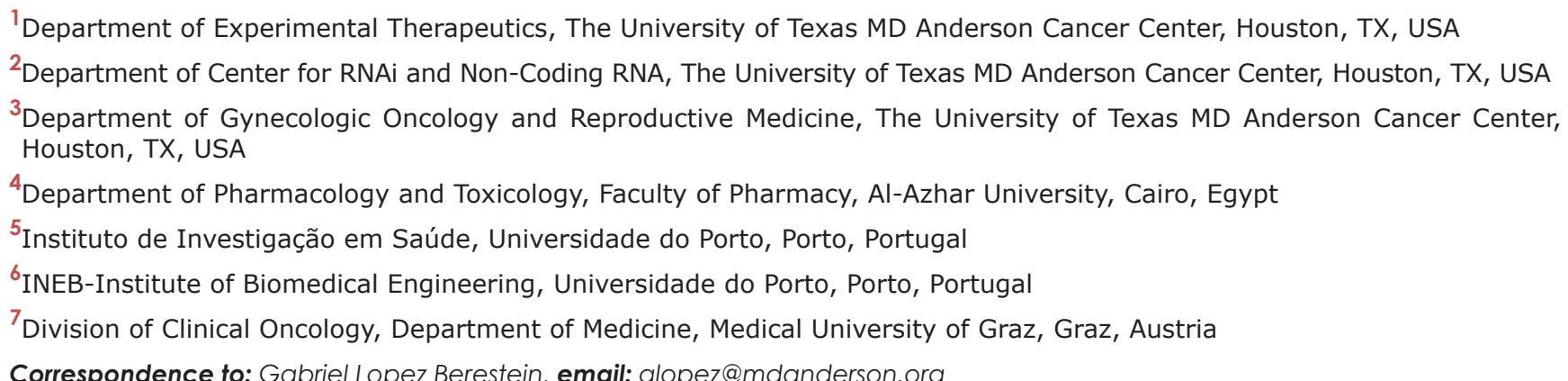 \\ Correspondence to: Gabriel Lopez Berestein, email: glopez@mdanderson.org
} Keywords: exosomes, ovarian cancer, miR-940, SRC, tumor suppressive Received: May 10, $2016 \quad$ Accepted: January 03, $2017 \quad$ Published: February 20, 2017

\section{ABSTRACT}

Exosomes have emerged as important mediators of diverse biological functions including tumor suppression, tumor progression, invasion, immune escape and cellto-cell communication, through the release of molecules such as mRNAs, miRNAs, and proteins. Here, we identified differentially expressed exosomal miRNAs between normal epithelial ovarian cell line and both resistant and sensitive ovarian cancer (OC) cell lines. We found miR-940 as abundant in exosomes from SKOV3-IP1, HeyA8, and HeyA8-MDR cells. The high expression of miR-940 is associated with better survival in patients with ovarian serous cystadenocarcinoma. Ectopic expression of miR-940 inhibited proliferation, colony formation, invasion, and migration and triggered G0/G1 cell cycle arrest and apoptosis in OC cells. Overexpression of miR-940 also inhibited tumor cell growth in vivo. We showed that proto-oncogene tyrosineprotein kinase (SRC) is directly targeted by miR-940 and that miR-940 inhibited SRC expression at mRNA and protein levels. Following this inhibition, the expression of proteins downstream of SRC, such as FAK, paxillin and Akt was also reduced. Collectively, our results suggest that OC cells secrete the tumor-suppressive miR-940 into the extracellular environment via exosomes, to maintain their invasiveness and tumorigenic phenotype.

\section{INTRODUCTION}

Ovarian cancer (OC) is one of the leading causes of death among women with gynecologic malignancies. According to the National Cancer Institute, approximately 21,290 new cases and 14,180 deaths were reported in 2015 [1]. Unfortunately, the majority of cases are diagnosed at an advanced stage, and an overall 5-year survival rate of approximately $40 \%$. At present, the mainstay of care for newly diagnosed OC is surgical debulking followed by adjuvant chemotherapy (mainly taxanes and platinum compounds) $[2,3]$. Most patients with $\mathrm{OC}$ relapse, highlighting the urgent need for new treatment strategies for the elimination of OC. Up to date, strategies targeting only tumor cells have proven to be unsuccessful to eliminate $\mathrm{OC}$ and prevent metastasis. Therefore 
understanding tumor and tumor microenvironment and identification of novel "molecular targets/ pathways" required for the development of the highly effective therapies to eradicate $\mathrm{OC}$ and improve patient survival.

Exosomes are small membrane-derived vesicles of about 30-140 $\mathrm{nm}$ that are thought to be shed from a variety of cell types [4]. Cancer cells have been shown to secrete exosomes in greater amounts than normal cells [5]. They can also be found in various body fluids under both healthy and morbid conditions $[6,7]$. Exosomes may carry various cargos from their donor cells, including membrane receptors, specific proteins and nucleic acids (DNA, mRNAs, miRNAs, and other non-coding RNAs), that can be translated into functions in the recipient cells [8]. The vesicles were initially proposed as a mechanism through which cells discard transferrin receptor during the maturation of reticulocytes [9].

MicroRNAs (miRNAs) are endogenous small, noncoding RNAs that act as post-transcriptional regulators of gene expression through the degradation of target mRNA or through translational inhibition [10]. Several studies have shown that miRNAs are involved in cell proliferation, intercellular signaling, cellular differentiation, apoptosis, and immune modulation $[11,12]$. miRNAs are aberrantly expressed in cancers, indicating that they may function as oncogenes or tumor suppressors in signaling pathways involved in cancer initiation and progression and in the development of metastasis $[13,14]$. Dysregulation of miRNA expression levels could be attributed to several mechanisms, including genomic deletion, mutation, or their active secretion as membrane-bound vesicular content and transfer to recipient cells $[15,16]$. For instance, tumor-suppressive miRNAs in the exosomes from normal epithelial cells inhibited the proliferation of cancer cells not only in vitro but also in vivo [17].

Several reports have shown that circulating miRNAs are associated with $\mathrm{OC}$ and correlate with disease detection, severity, and response to treatment [18-22]., but the function of these exosomal miRNAs remains elusive and poorly understood. Therefore, identifying the oncogenic and tumor suppressor exosomal miRNAs is an important step toward developing new strategies for both the diagnosis and treatment of OC.

In the present study, we hypothesized that the release of miRNAs from OC cells into extracellular fluids via exosomes is a selective process, and the relative abundance of tumor-suppressive miRNAs are higher in exosomes from OC cells compared with their cellular expression or exosomes derived from normal ovarian cells. We also hypothesized that the secretion of the suppressor miRNAs by cancer cells results in depletion of these miRNAs and intracellular activation of oncogenic pathways. In this study, we selected miR-940 since we observed that its expression was higher in three different ovarian cancer cell exosomes compared to normal epithelial ovarian cell exosomes.

\section{RESULTS}

\section{Exosome isolation and characterization}

Initially, for the purpose of profiling exosomal miRNAs, we first isolated exosomes from culture media of six OC cell lines after 24 hours of incubation using total exosome isolation reagent as described in Materials and Methods. Previously, the most common method for isolating exosomes from cultured cell media was differential centrifugation, which is very time consuming and requires extensive training to ensure successful isolation of exosomes. Although polymer-based exosome extraction technologies may co-precipitate other proteins and vesicles, we selected a commercial reagent as a translatable means of obtaining enriched exosome-derived RNA from small-volume samples, an approach validated by other researchers [23-25]. To confirm the efficiency of the isolation method and the quality of the vesicles, we followed an extensive characterization.

We assessed the morphology and size using Atomic Force Microscopy (AFM), which showed that the isolated exosomes appeared as vesicles with characteristic circular structures in 3D topography (Figure 1a). We analyzed $\sim 320$ vesicles and found that the mean size of OC-derived exosomes was $51.01 \mathrm{~nm}$ (Supplementary Figure 1a). This size is consistent with previously reported characteristics of exosomes $[15,26]$. Since the characteristic shape and size of exosomes are distinct from any other structures seen on the surface, the height profile of 3 individual exosomes and the size distribution of exosomes are shown in Supplementary Figure 1b, which shows near homogeneity with respect to height and width.

Because AFM examines only pelleted or solid surface-bound vesicles, we next selected Nanoparticle Tracking Analysis (NTA), which is suitable for studying particle size in suspension. The NTA for SKOV3ip1 revealed an average mode value of $104 \pm 4.3 \mathrm{~nm}$ (Figure 1b).

We further evaluated by Western blotting the expression of several exosome markers in proteins isolated from all six OC cell lines. Three well-known exosomal markers, CD63, CD9, and Hsp70, were found to be present in all OC-derived exosomes [4, 27]. (Figure 1c, upper panel). Cytochrome c, a mitochondrial protein, was detectable in whole-cell lysates but absent in the exosomes, indicating that the exosome preparations were not contaminated with apoptotic vesicles (Figure 1c, lower panel). CD63 was used as a control for exosome expression. Together, these findings verified that the examined vesicles were exosomes and could be isolated in a consistent manner. 


\section{MicroRNA profiles of exosomes and their parental cells and validation by qRT-PCR}

To confirm whether RNA was properly conserved in exosome samples, we examined total RNA isolated from $\mathrm{OC}$ exosomes and their cells of origin using an Agilent Bioanalyzer 2100. Consistent with previous studies of exosomes from other cell types [28-30], the exosomal RNA showed little or no peaks of $28 \mathrm{~S}$ and $18 \mathrm{~S}$ ribosomal RNA compared to cellular RNA, whereas the characteristic peak of small RNA was detected below 200 nucleotides (Figure 2a and Supplementary Figure 2b).

Next, we evaluated miRNAs differentially expressed in exosomes versus their cells of origin, using the Affymetrix GeneChip miRNA 4.0 microarrays, which contain 36,353 unique probes based on miRBase v20. After the normalization of each miRNA across all samples, one-way ANOVA was performed to identify significantly expressed mature miRNAs. To identify the most prominent miRNAs that were differentially expressed in exosomes versus cells, we restricted the criteria for upregulation as ANOVA corrected $P<0.05$ and a fold change of $\geq 5$ and the criteria for down-regulation as ANOVA corrected $P<0.05$ and a fold change of $\leq-5$.

Microarray analysis showed that certain miRNAs were expressed at higher levels in exosomes than in their donor cells and vice versa (Figure 2a and Additional File 1), which may suggest cell type-specific mechanisms for highly selective enrichment or exclusion of the miRNA in exosome-mediated secretion. Several miRNAs (miR-940, miR-1281, miR-1825, miR-3921, and miR-6877-3p) were significantly more abundant in exosomal samples from SKOV3IP1, HeyA8, and HeyA8-MDR OC cells, whereas other miRNAs (miR-1246, miR-122-5p, miR-6126, miR-

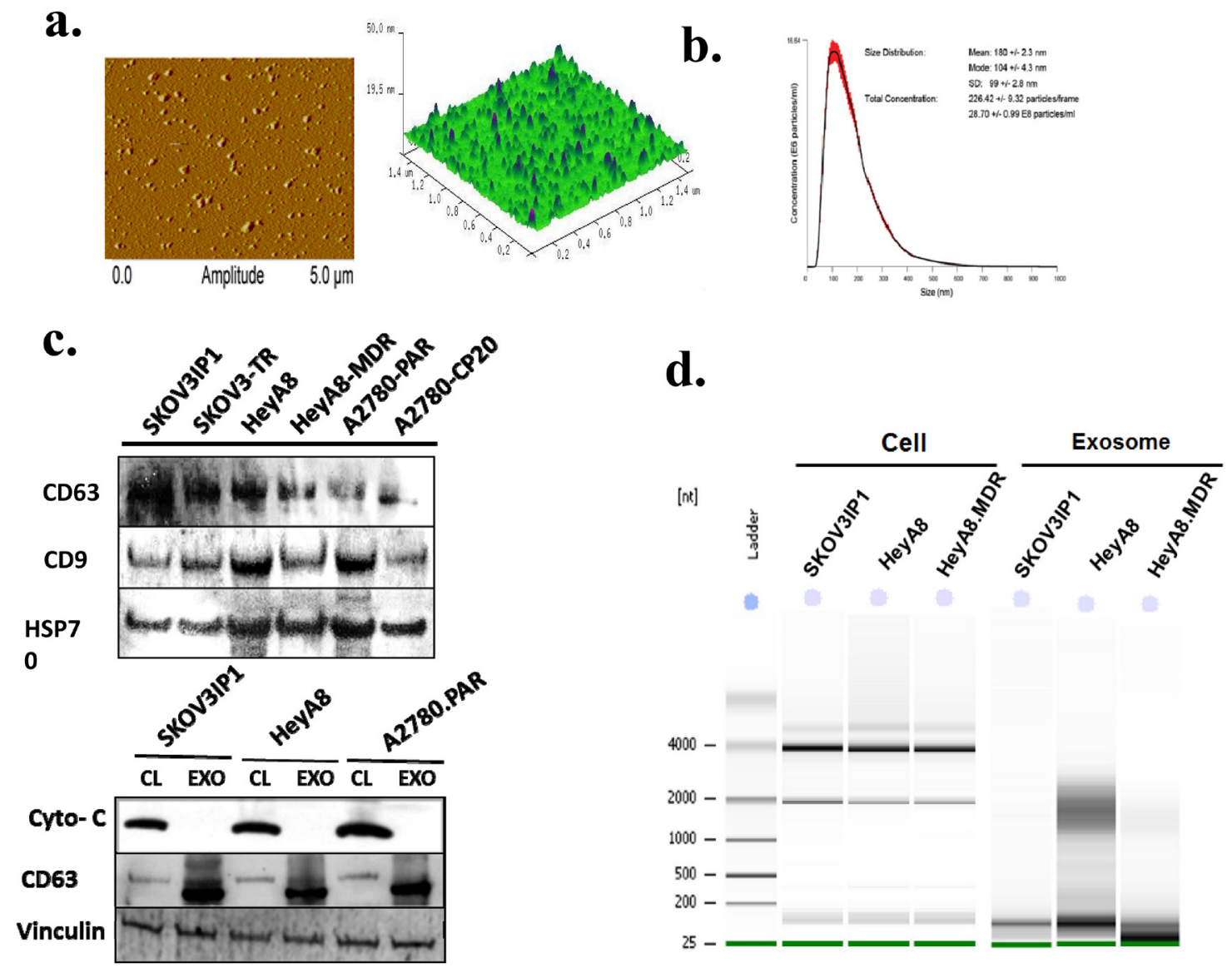

Figure 1: Characterization of exosomes and exosomal miRNA isolated from ovarian cancer cells. a. Atomic force microscopy images of exosomes showing the morphology and size distribution of vesicles. Exosomes appeared as isolated vesicles with characteristic round-shaped structures in a 3D topographic image. b. Nanoparticle tracking analysis (NTA) of SKOV3IP1 exosomes. The graph represents the size distribution of particles in solution showing an average of the mode size of $104 \mathrm{~nm}$. c. Upper panel: Western blot analysis of ovarian cancer derived exosomes. Exosomal marker proteins CD63, CD9, and HSP70 were detected in exosome preparations. Lower panel: Cytochrome C (Cyto-c) was detected in cell lysates (CL) but was not detectable in exosomes (EXO), which may indicate that the exosome preparations were not contaminated by apoptotic body vesicles. CD63 and vinculin are used as loading controls. Each experiment was replicated 3 times and representative blots are depicted. d. Exosome and cellular RNA were analyzed using the Agilent 2100. Gel obtained with Agilent 2100 Bioanalyzer showing the relative increase in the exosomes of small RNAs (below 200 nucleotides), including miRNAs, but no or very low amount of ribosomal RNA (18S- and 28S- rRNA) compared to their donor cells. 
$6780 \mathrm{~b}-5 \mathrm{p}$, and miR-4484) were more abundant in both $\mathrm{OC}$ and normal exosomes than in their originating cells (Figure 2b).

To identify the potential roles of exosome-derived miRNAs, we focused on the 5 miRNAs that were highly enriched in OC-derived exosomes and not elevated in normal exosomes. We excluded miR-6780b-3p, since it is a new miRNA and has no predicted targets by most target prediction algorithms. As an initial step toward understanding the function of the preferentially exported miRNAs, we attempted to determine the genes being targeted by these miRNAs. We employed DIANA microTCDS, which has been shown to perform well in terms of sensitivity and specificity compared to other available algorithms [31].

The genes predicted to be targeted by one or more of the most selectively exported miRNAs are listed in Additional File 3. Functional analysis of these genes revealed that the most enriched pathway was adherens junction (hsa04520) $(P=1.48 \mathrm{E}-09)$, which contained 20 predicted target genes (Supplementary Figure 3). All the enriched pathways are listed in Additional File 4. We focused in particular on miR-940 for further studies as it is novel and has never previously been associated with OC. Next, we examined the intracellular and extracellular levels of miR-940 in different OC cells by real time PCR.
The expression of miR-940 was higher at the secretory level than at the endogenous level (Figure 3a). The outcomes were consistent with the normalized microarray data (Figure 3b). Interestingly, microRNA expression levels were examined in OC and normal exosomes, miR940 was also significantly higher in OC exosomes than in normal exosomes (Figure 3c), which is in line with the microarray data (Additional File 2). We, then analyzed the effect of miR-940 in ovarian cancer patient survival by Kaplan-Meier plots. The Cancer Genome Atlas (TCGA) data revealed that high expression of miR-940 is associated with better survival in patients with ovarian serous cystadenocarcinoma (Figure $3 \mathrm{~d}$ ).

\section{MicroRNA-940 overexpression suppresses OC cell proliferation and colony formation and induces $\mathrm{G0} / \mathrm{G} 1$ cell cycle arrest}

Because the expression of miR-940 was significantly lower in OC cell lines than in their exosomes, we next focused on the functional effects of miR-940 on OC cells. MiR-940 and miR control were transiently transfected into HeyA8 and HeyA8-MDR cells. qRT-PCR analysis showed that miR-940 was remarkably $\left(\sim 1.7 \times 10^{3}\right.$ fold and $\sim 14 \times 10^{3}$ fold) increased in HeyA8 and HeyA8-MDR cells, respectively transfected with miR-940 mimics compared

\section{a.}
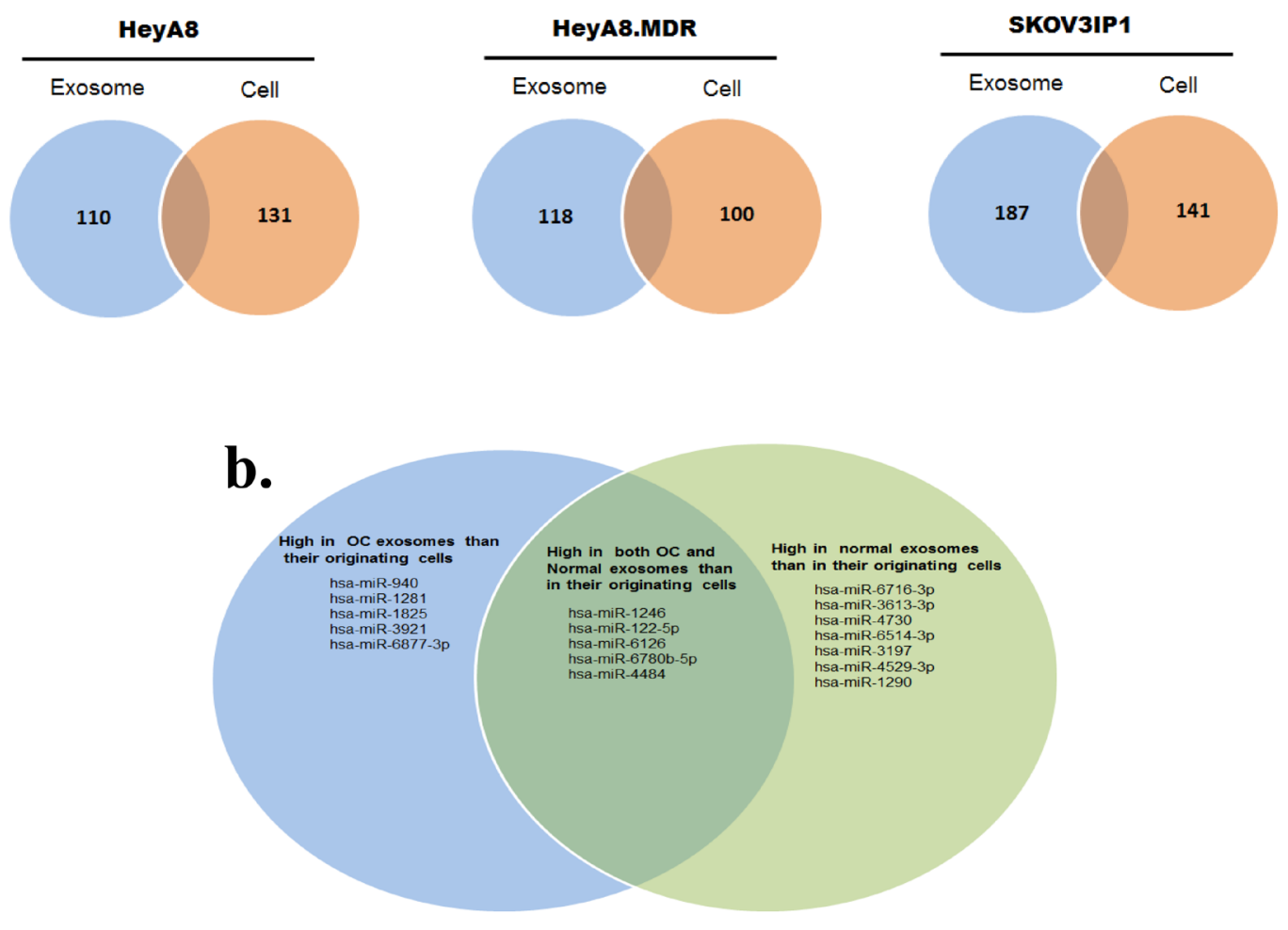

Figure 2: Profiling of miRNAs isolated from OC cells and their corresponding exosomes. a. Venn diagrams based on miRNA microarray results showing the miRNAs most enriched in exosomes or in their respective donor cells. b. Venn diagram showing the miRNAs highly enriched in OC-derived exosomes versus normal exosomes and vice versa. 
to miR-mimics control (Figure 3d). To determine whether overexpression of miR-940 has an effect on cell growth in OC, we performed a proliferation assay in OC cell lines. The results of the MTS assay showed that miR-940 overexpression significantly reduced the growth rates of both

a.

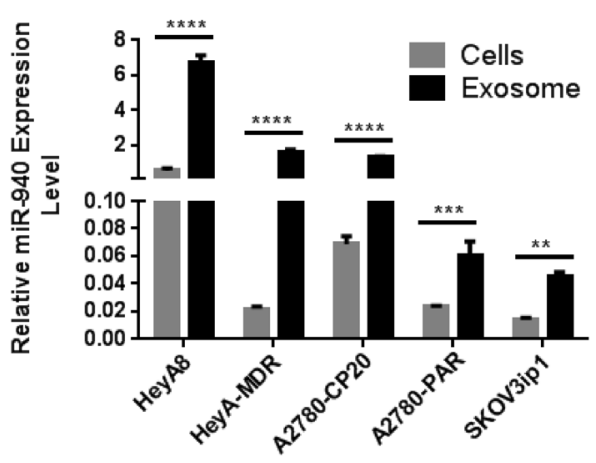

c.

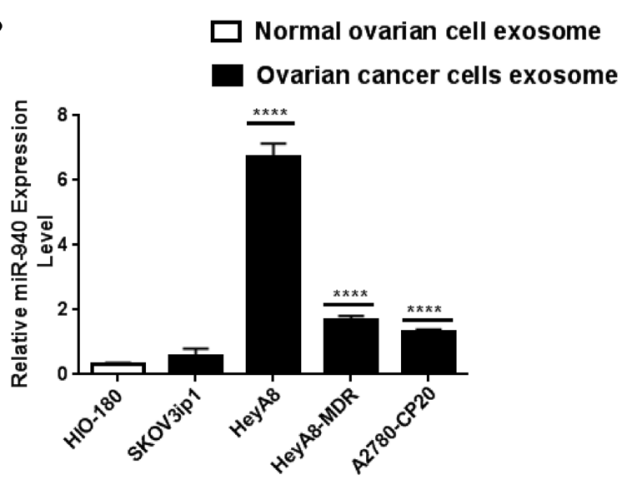

e.

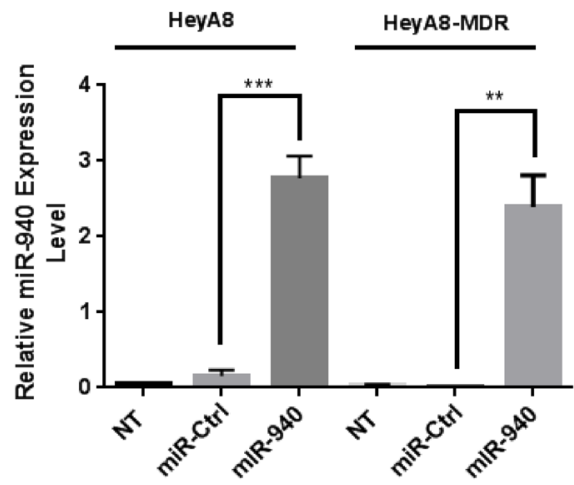

HeyA8 and SKOV3IP1 cells, by 40\% $(p<0.0001)$ and 45\%, respectively $(p<0.0001)$ (Figure $4 \mathrm{a}$ ). Colony formation assays further confirmed the anti-proliferative function of miR-940 in OC cells (Figure 4b). Concomitant with this inhibition of cell proliferation, there was a significant cell

b.

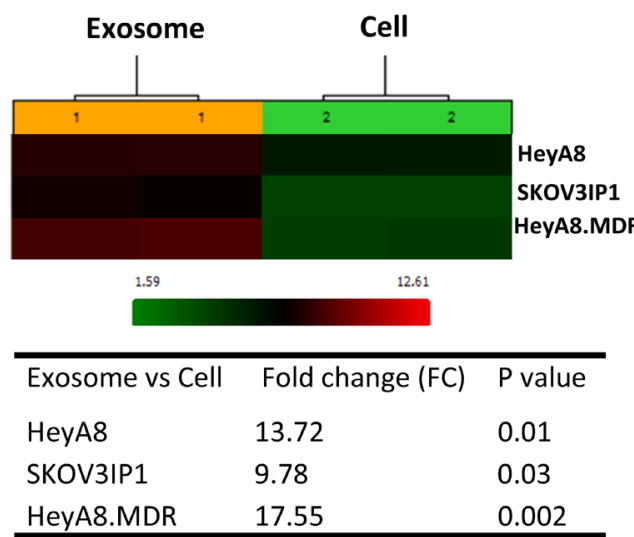

d.

TCGA OV miR-940 (MIMAT0004983)

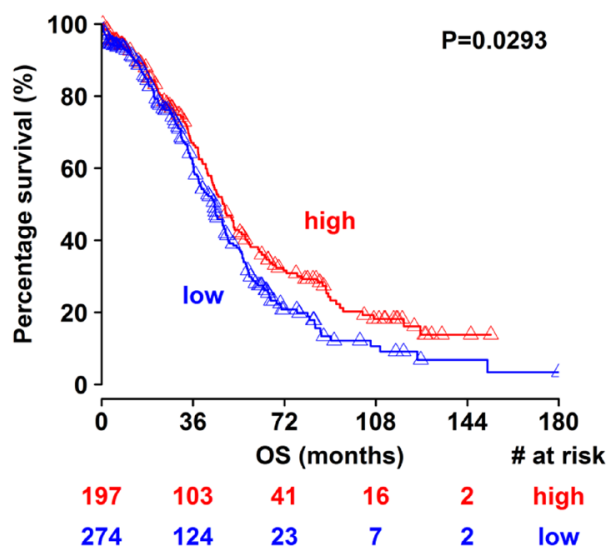

Figure 3: Relative expression of miR-940 in ovarian cells and their exosomes. a and $\mathbf{b}$. Relative expression of miR-940 shows significant up-regulation in exosomes compared to their originating cancer cells ( $P$ values obtained with Student's $t$-test; ** $P<0.01$; *** $P$ $<0.001$ or $* * * * P<0.0001$; bars and error bars represent mean values and the corresponding standard error (SE)). c. Expression levels of miR-940 are significantly higher in OC cells derived exosomes than exosomes derived from HIO180 non-transformed ovarian cell line $(* * * * P<0.0001)$. d. Kaplan-Meier plots for miR-940 expression in ovarian cancer patients (The Cancer Genome Atlas data). High expression of miR-940 is associated with better survival. e. Ectopic expression of miR-940 in OC cell lines HeyA8 and HeyA8-MDR were evidence by qRT-PCR after transfection. 
cycle arrest in the G1 phase, which was evidenced by an approximately $63 \%$ and $33 \%$ increase in the percentage of HeyA8 and HeyA8-MDR cells, respectively accumulating in the G0/G1 phase, accompanied with a decrease in the $\mathrm{S}$ phase population in both cell lines (Figure 4c).

\section{Ectopic expression of miR-940 induces cell apoptosis by regulating caspase-dependent apoptosis pathways}

Inhibition of cell growth in cancer cells is usually associated with concomitant activation of cell death pathways. We therefore examined the contribution of apoptosis to growth inhibition mediated by miR940 overexpression. We evaluated the rate of cellular apoptosis using Annexin V and PI staining for flow cytometry. The number of both early and late apoptotic HeyA8 and HeyA8-MDR cells at 72 hours posttransfection of miR-940 was substantially higher by $\sim 5$ fold and 2-fold, respectively than the number of control miRNA transfected cells (Figure 5a). The induction of apoptosis was further confirmed by the expression of apoptosis-related proteins including PARP, caspase-3, caspase-9, survivin, and PTEN on Western blot (Figure 5b).
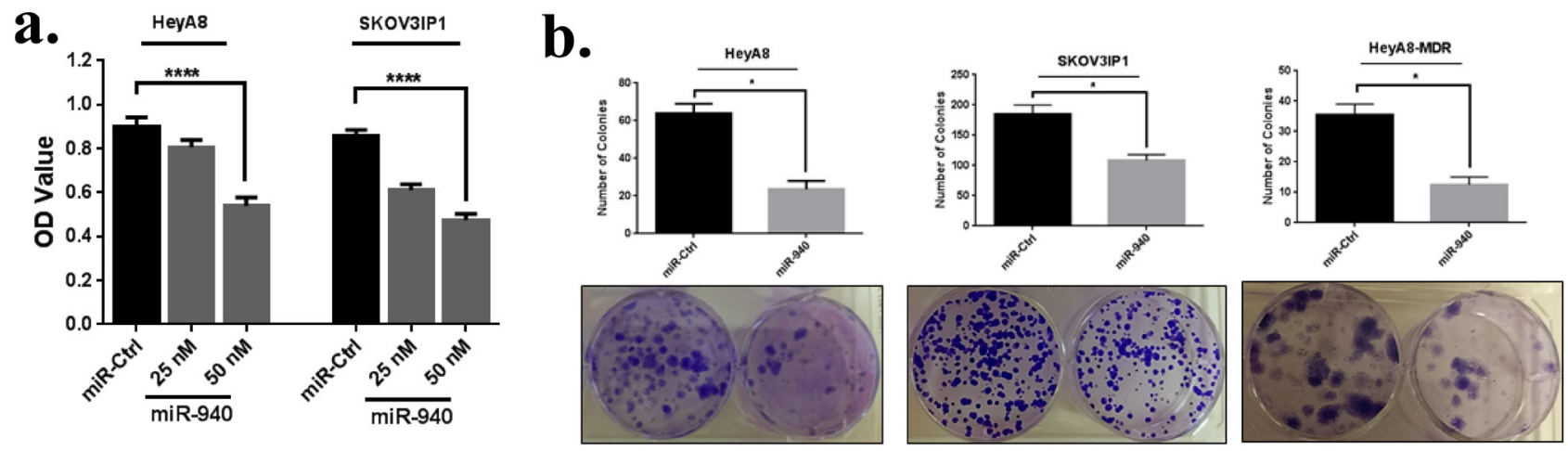

\section{c.}
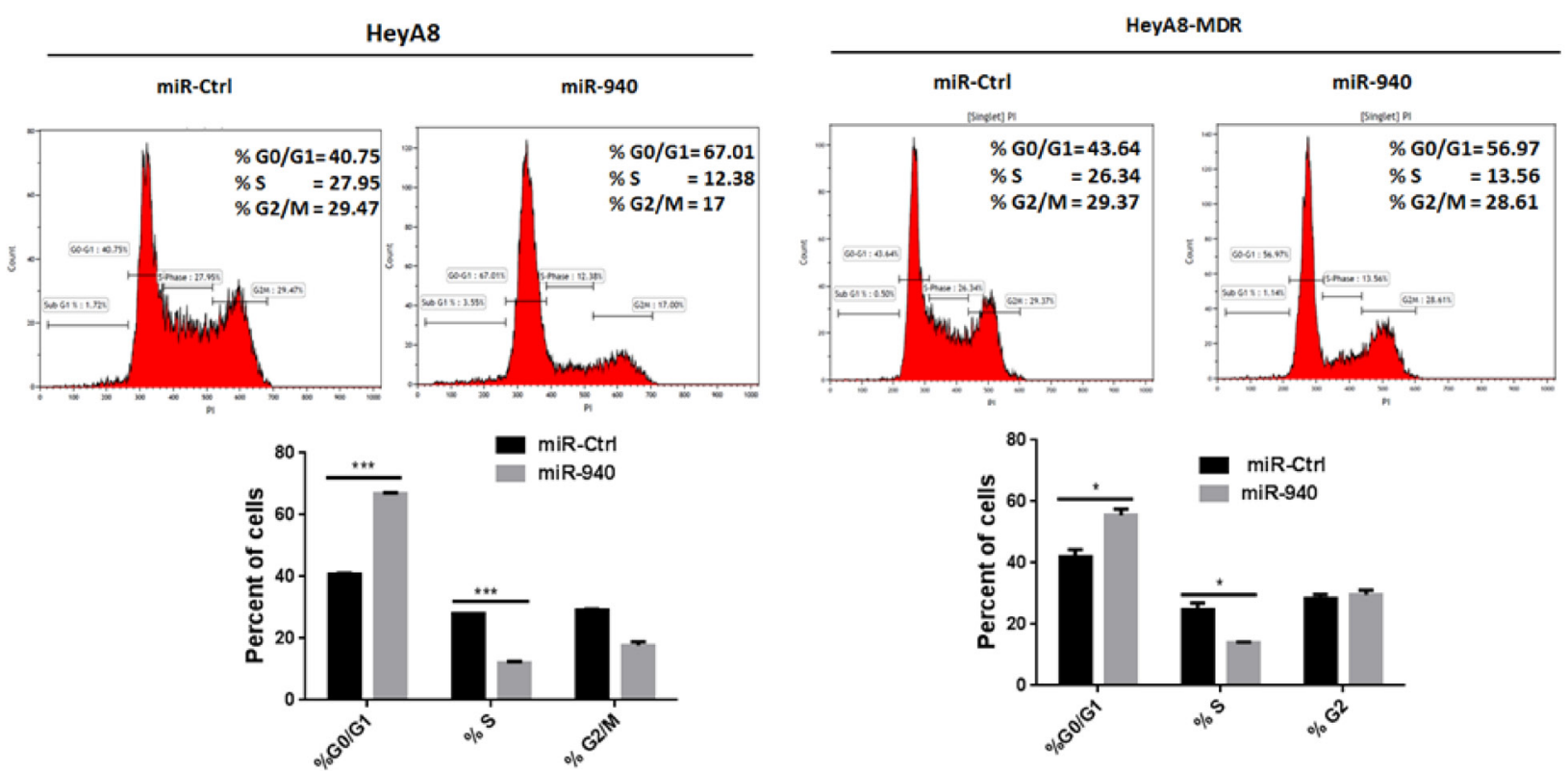

Figure 4: miR-940 inhibits OC cell growth in vitro and induces G0/G1 cell cycle arrest. a. Overexpression of miR-940 significantly inhibited HeyA8 and SKOV3IP1 cells viability. Cells were transfected with indicated miRNAs, and after $72 \mathrm{~h}$, Cell growth rates were detected by MTS assay. Data are represented as mean \pm SE. $* * * * P<0.0001$ versus control cells from three independent experiments. b. Ectopic expression of miR-940 significantly inhibited colony formation in HeyA8, HeyA8-MDR and SKOV3IP1 cells $(* P$ $<0.05$ indicate significant difference compared with control group). The results are presented as means \pm SE ( $n=3$ for each panel). c. Cellcycle arrest analysis of HeyA8 and HeyA8-MDR cells after $72 \mathrm{~h}$ transfection with miR-940. Cells were harvested at $72 \mathrm{~h}$ and were fixed, stained with propidium iodide (PI) and analyzed by fluorescence-activated cell sorting. Data are presented as the percentage of cells as mean $\pm \mathrm{SE}$. ${ }^{*} \mathrm{P}<0.05,{ }^{*} * \mathrm{P}<0.001$ (Student's t-test). Two independent experiments were performed and the representative one was shown. 


\section{MicroRNA-940 inhibits the invasiveness and migration of $\mathrm{OC}$ cells}

To further determine the effects of miR-940 on malignant phenotypes of OC cells, we assessed whether miR-940 could alter the invasion and migration of OC cells by performing an in vitro matrigel invasion assay and wound-healing assay in HeyA8, HeyA8-MDR, and

a.
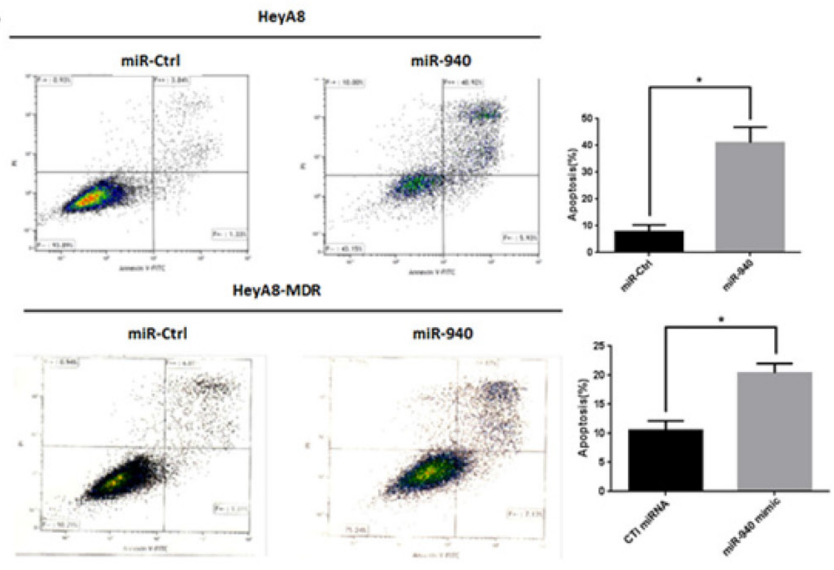

C.

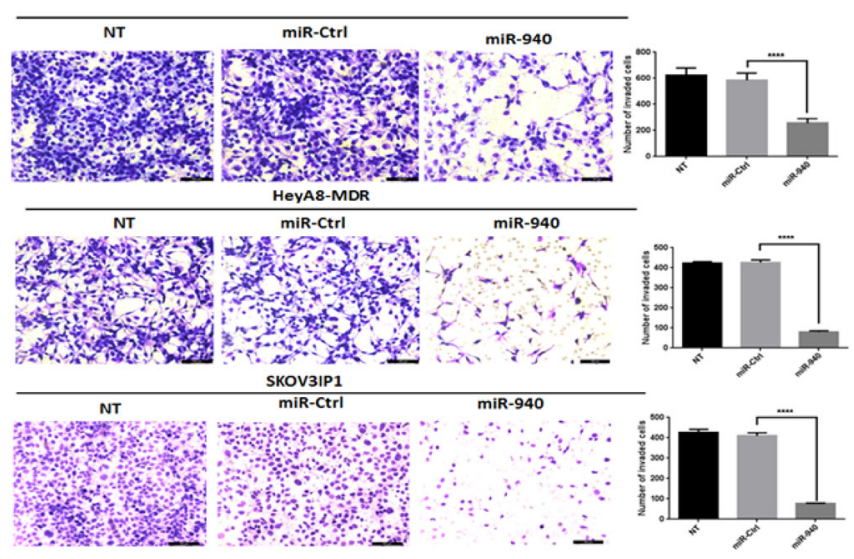

d
SKOV3IP1 cells. These assays mimic the in vivo migration and invasion process $[32,33]$. Ectopic overexpression of miR-940 significantly reduced the number of invading HeyA8, HeyA8-MDR, and SKOV3IP1cells by about $56 \%, 80 \%$ and $80 \%$, respectively in comparison with miRcontrol (Figure 5c). Furthermore, the wound-healing assay demonstrated that transient overexpression of miR-940 significantly decreased the ability of OC cells to migrate

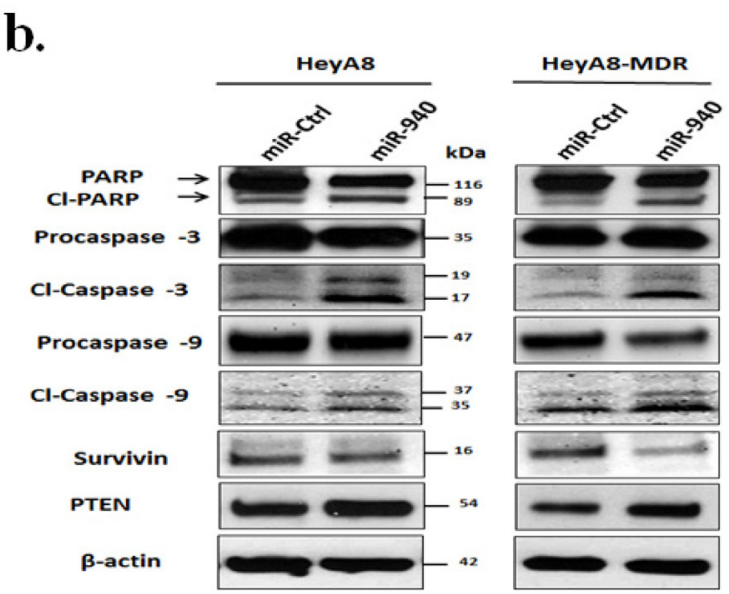

d.

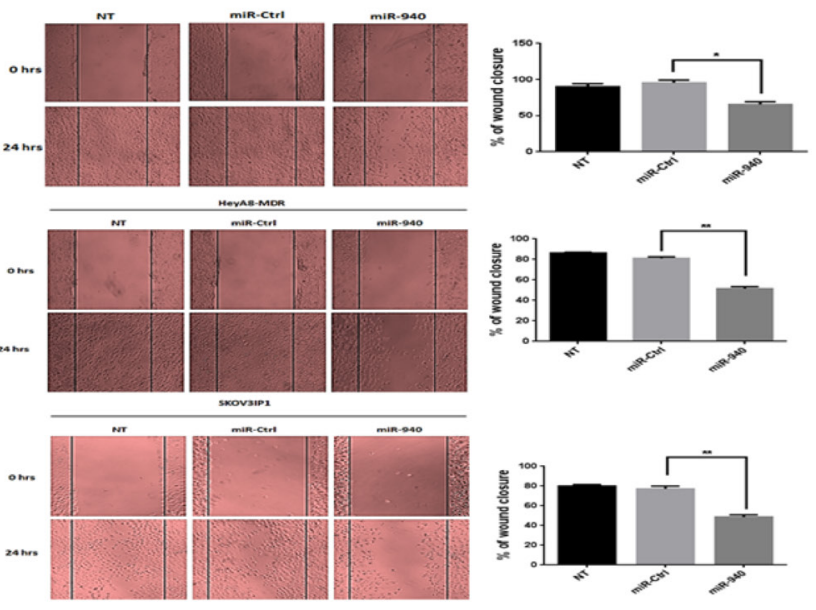

Figure 5: Transient transfection of miR-940 triggers apoptosis and suppresses the invasiveness and migration of OC cells. a. Ectopic expression of miR-940 triggered apoptosis in HeyA8 and HeyA8-MDR cells. Cells were transfected with miR-940 or control mimic, and analyzed by Annexin V-FITC and PI double-staining and positive cells were detected and quantified by FACS analysis. The represented percentages show positive cells at both early and late apoptosis. Data are represented as mean $\pm \mathrm{SE}$. $* \mathrm{P}<0.05$ indicates significant difference compared with control group. All experiments were independently performed three times. b. Apoptoticrelated proteins expression was detected by western blot. miR-940 induced apoptosis was manifested after $72 \mathrm{~h}$ of transfection, by increase in cleavage of Caspase-3, 9 and PARP as well as a marked decrease in anti-apoptotic Survivin with a concomitant increase in PTEN. $\beta$-actin was used as a loading control. c. Invasion assay showed a significant decrease in the number of invading HeyA8, HeyA8-MDR and SKOV3IP1 cells transfected with miR-940. Cells were transfected with indicated miRNAs and seeded onto Matrigel-coated Transwell filters in Matrigel invasion chambers. The invaded cells in a minimum of four random selected fields were counted and data are presented as mean $\pm \mathrm{SE}$. Each experiment was performed at least in triplicate. ${ }^{* * * *} P<0.0001$ indicates significant difference versus control. d. Wound healing assay showed that the migration of OC cells was significantly decreased after transfection of miR-940 mimics compared with control groups. A single scratch was made in the center of the confluent cell monolayer, and the wounded monolayers were transfected with indicated miRNAs. The migration distance was measured at 0 and $24 \mathrm{~h}$ after the cells had been scratched. The data is expressed as mean of the percentages of wound closures $\pm \mathrm{SE}$ of three independent experiments. $(* \mathrm{P}<0.05 ; * * P<0.01$ represent significant difference between indicated groups. 
(Figure 5d). Compared with the negative control miRNA, miR-940 expression reduced HeyA8, HeyA8-MDR, and SKOV3IP1 cells migration by $31 \%, 36 \%$ and $37 \%$, respectively. These results indicate that miR-940 strongly inhibits OC cell invasion and metastasis potential.

\section{MicroRNA-940 directly represses proto- oncogene SRC kinase and its downstream genes involved in proliferation, invasion and migration pathways in $\mathrm{OC}$}

To investigate the underlying molecular mechanisms of miR-940 in OC growth and metastasis, we searched for the putative target genes of miR-940 using online prediction tools, such as TargetScan [34] and DIANA microT [35]. Because miR-940 was able to inhibit OC proliferation and invasion, we focused on the genes that promoted tumor progression and metastasis. Among the hundreds of different targets predicted, SRC was notable because it is overexpressed in a number of malignancies, such as colorectal cancer, lung cancer, and pancreatic cancer [36-38]. Furthermore, our previous studies demonstrated that SRC expression was markedly upregulated in $\mathrm{OC}$ and involved in a variety of cellular functions, including cell proliferation, invasion, and migration [39-41].

Using the target prediction databases, 2 potential binding sites of the $3^{\prime}$-UTR of SRC were predicted (Figure 6a). To assess the regulation of these 2 predicted binding sites, we constructed luciferase reporter plasmids containing SRC 3'UTR sequences (3'UTR-WT1 and 3'UTR-WT2) or with mutated putative miR-940 target sites (3'UTR-Mut1 and 3'UTR-Mut2). After transient cotransfection of HEK293 cells with WT-SRC plasmids, the luciferase activity of miR-940 transfected cells was significantly lower than that of control miRNA transfected cells, while the inhibitory effect of miR-940 on luciferase activity was abolished in mutant construct, Mut-1 and Mut-2(Figure 6b).

Next, we measured protein expression levels of SRC $(60 \mathrm{kDa})$ by Western blot analysis in different OC cell lines and in HIO-180 non-transformed ovarian epithelial cells (Figure 6c). SRC protein was highly expressed in HeyA8 and HeyA8-MDR cells, but its expression was lower in HIO-180 cells. SRC mRNA basal levels were higher in most of the OC cell lines tested than in HIO-180 cells (Figure 6d). The results indicated that the endogenous level of SRC expression was directly associated with that of miR-940 in exosomes.

Because of these observations, we sought to determine whether the tumor suppressor function of miR940 in OC was attributable to its suppressive effect on $\mathrm{SRC}$ expression. Thus, we examined the effect of miR-940 on the endogenous SRC expression level via qRT-PCR and Western blotting in HeyA8 and HeyA8-MDR cells. Transfection with the miR-940 mimic led to an obvious down-regulation of SRC protein and mRNA expression levels in both HeyA8 and HeyA8-MDR cells (Figure 6e, 6f, respectively). Western blot analysis showed reduced levels of SRC downstream molecules that are involved in cell proliferation, migration, and invasion following miR-940 overexpression (Figure $6 \mathrm{~g}$ ). We also determined the effect of miR-940 overexpression in normal ovarian cells (HIO-180) by wound healing assay (Supplementary Figure 4). miR-940 treatment also decreased the migration ability of HIO-180 cells.

Furthermore, we performed rescue experiments using SRC lentiviral vector to overexpress SRC protein in ovarian cancer cells. Over expression of SRC was analyzed by westernblot (Supplementary Figure 5a). Ectopic expression of miR-940 rescued the increased invasive and migratory effect of SRC in ovarian cancer cells. Transfecting cells with miR-940 mimic decrease the migration ability of cells compared to CTL miRNa transfected cells. As expected, the effect of miR-940 treatment on the open wound area in CTL lentiviral transfected cells is smaller than that in SRC lentiviral transfected cells (Supplementary Figure 5b). We observed the same patter in invasion assay (Supplementary Figure 5c). However, we did not observe significant decrease in apoptotic protein levels; such as Caspase-3 and PARP (Supplementary Figure 5d).

The ability to modulate SRC protein and its downstream genes levels might explain, at least in part, why miR-940 can inhibit cell proliferation and invasion in OC. Moreover, the amount of exosomal miR-940 was much greater in HeyA8 and HeyA8-MDR cells than in the other OC cell lines and normal ovarian HIO-180 cells. Interestingly, the endogenous levels of miR-940 target SRC were higher in HeyA8 and HeyA8-MDR cells than in other cells, suggesting that both OC cell lines selectively and actively secreted miR-940 into the extracellular environment via exosomes to maintain the activity of $\mathrm{SRC}$ and its downstream genes that are involved in tumorigenesis.

We also used combination treatment to test cancer cell invasion in vitro. We found that combination treatment resulted in synergistic effect on invasiveness of ovarian cancer cells (Supplementary Figure 6). miR-940 treatment in combination with SRC siRNA led to significantly lower number of invaded cells compared to SRC siRNA alone $(\mathrm{p}<0.05)$.

\section{Systemic delivery of miR-940 by DOPC nanoparticles suppresses ovarian tumor growth in vivo}

On the basis of our in vitro findings, we next sought to determine whether miR-940 delivery affected tumor growth and whether SRC targets could be down regulated by its delivery in vivo. For these studies, we established OC orthotopic mouse models by intraperitoneally injecting 
a.
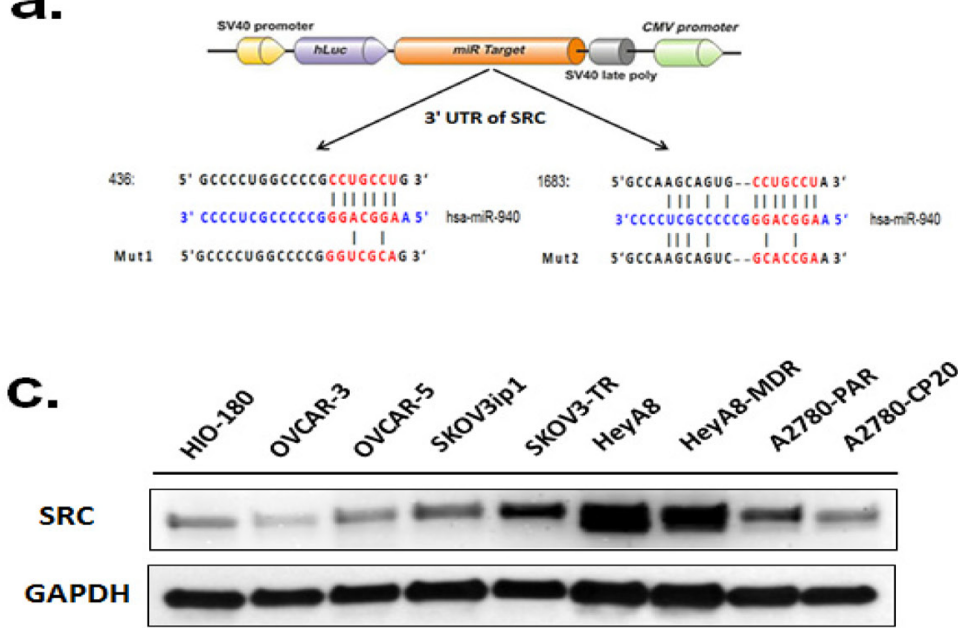

e.

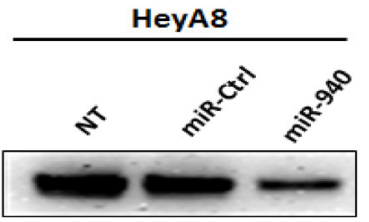

SRC
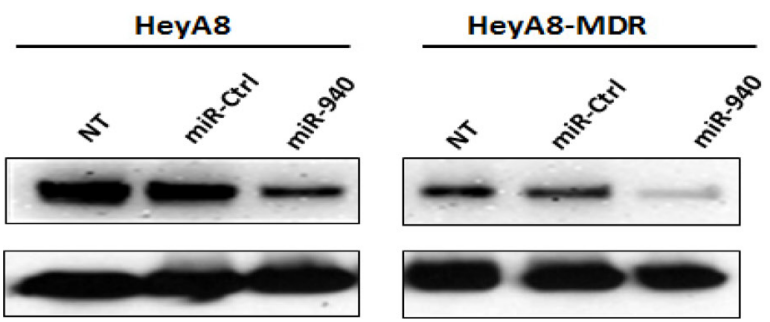

g.

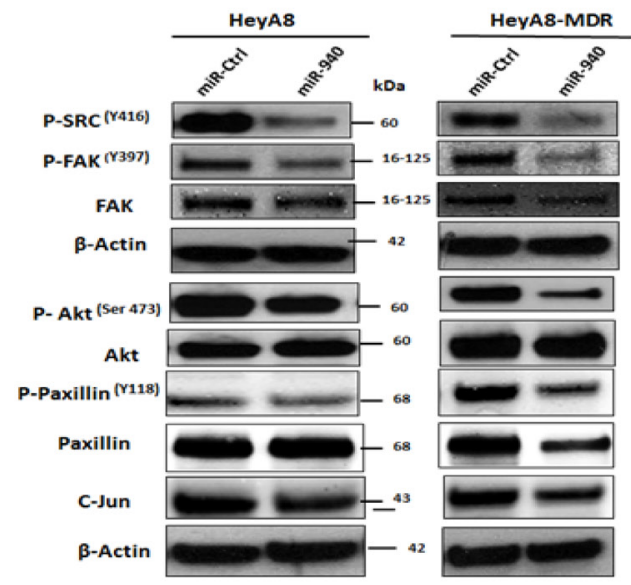

b.

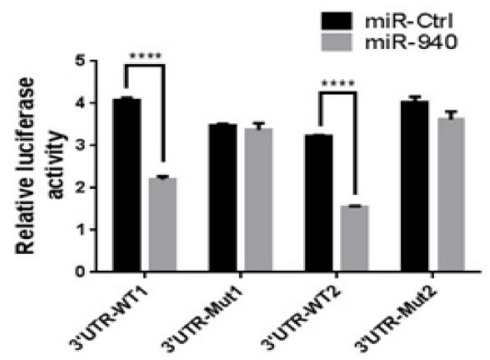

d.

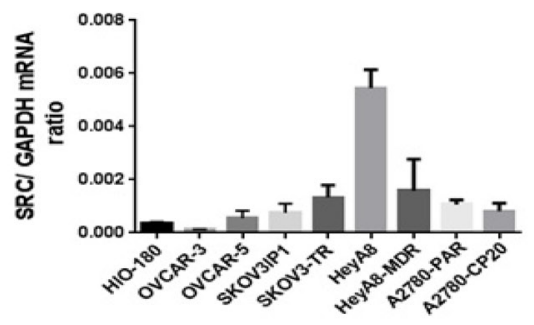

f.

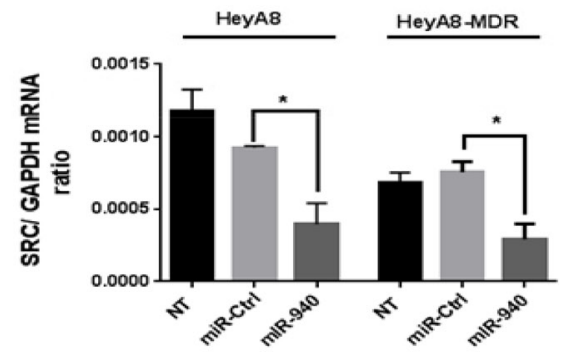

Figure 6: Proto-oncogene SRC kinase is a direct target of miR-940. a. Sequence alignment of the wild-type (WT) and mutant (MUT) SRC 3'-UTR, indicating the potential binding sites for miR-940. The seed regions of miR-940 and the seed-recognizing sites in the SRC 3'-UTR are indicated in red. b. Luciferase reporter assay of HEK-293 cells which were co-transfected with the luciferase reporter plasmid containing the wild-type (WT) or mutant (MUT) 3'UTR of SRC gene and $50 \mathrm{nM}$ of either miR-940 mimic or control mimic. Luciferase activity was determined using the dual luciferase assay and shown as the relative firefly activity normalized to renilla activity. Significant differences was found between scramble and miR-940 on wild-type 3'UTR construct but not with construct carrying a mutated seed region. The data are shown as mean \pm . SE of three separate experiments. ${ }^{*} * * \mathrm{P}<0.0001$ indicates significant difference compared with control group. c. Expression levels of SRC in different ovarian cell lines detected by western blot. Levels of GAPDH were evaluated as an internal control for loading. $\mathbf{d}$. Expression levels of SRC mRNA in ovarian cancer cells detected by real-time PCR. The mRNA expression levels were normalized against GAPDH. e. Measurement of SRC protein expression levels in HeyA8 and HeyA8. MDR cells by western blot analysis following transfection with the miR-940 mimic or miR-Ctl. $\beta$-actin was used as an internal control. f. Measurement of SRC mRNA expression levels in HeyA8 and HeyA8. MDR cells by RT-qPCR following transfection with the miR-940 mimic or miR-Ctl. GAPDH was used as an internal control. g. Expression of the downstream targets of SRC upon transfection of miR-Ctl or miR-940 in HeyA8 and HeyA8. MDR cells. As shown miR-940 significantly regulates SRC and its downstream genes. Cells were transfected with indicated miRNAs, and cell lysates were subjected to Western blot analysis. $\beta$-actin was used as a loading control. Three independent experiments were performed with similar results, and representative data are shown. 
mice with HeyA8 cells and treating them with miR-940DOPC or miR-Ctrl-DOPC. We found that tumors removed from mice treated with miR-940-DOPC were significantly smaller and weighed $85 \%$ less $(p=0.0459)$ than those of mice treated with miR-Ctrl-DOPC $(* \mathrm{P}<0.005)$ (Figure $7 \mathrm{a}$. No toxicity was observed for any treatment group as indicated by no change in mouse body weight (Figure 7b). Importantly, the isolated tumor tissues were subjected to immunohistochemistry for Ki67 staining to examine the biological effects of miR-940 on tumor cell proliferation

\section{a.}

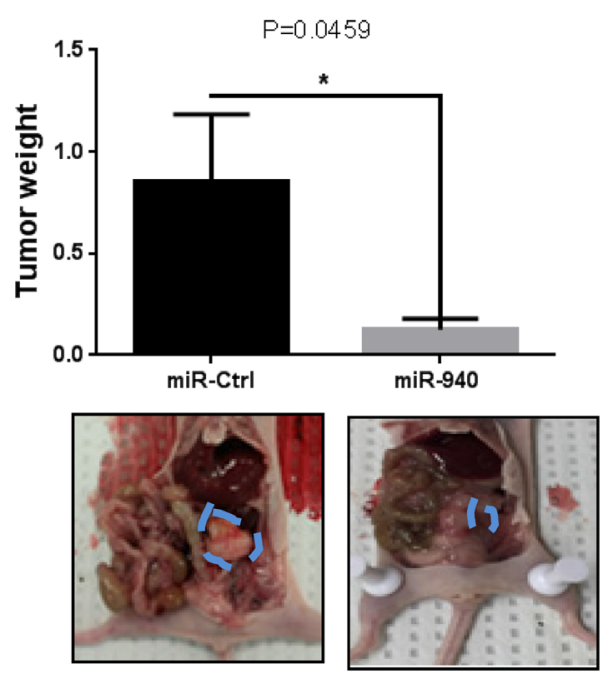

\section{c.}
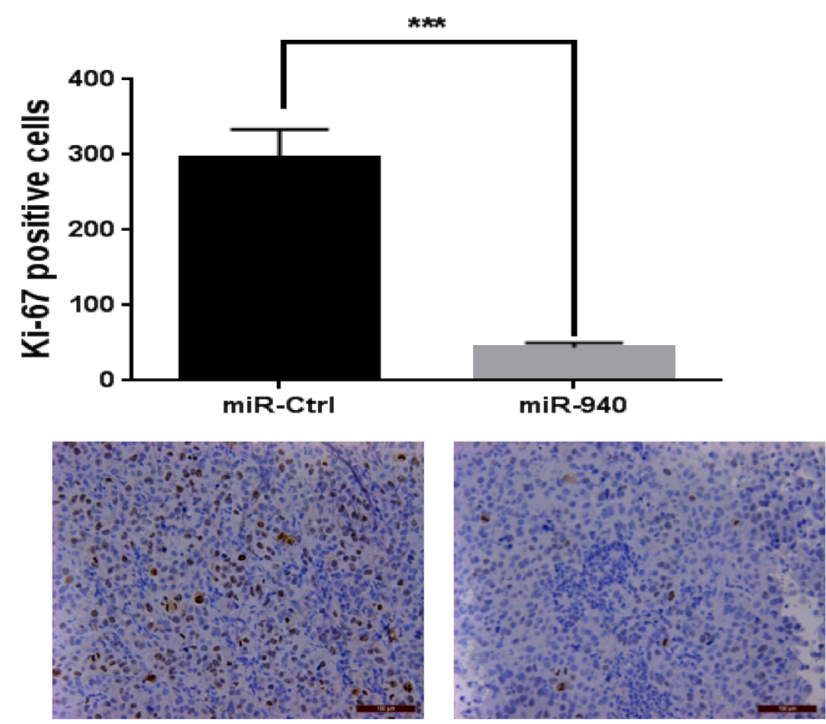

[42]. Tumor of mice treated with miR-940 mimic showed $85 \%$ reduction in cell proliferation as compared with control group (Figure 7c). These in vivo findings were consistent with the in vitro results observed in the cell proliferation assays, demonstrating that miR-940 has a tumor-suppressive function.

We, next, examined SRC expression levels in tumors by qPCR (Figure 7d). SRC mRNA levels were significantly decreased in miR-940 treatment groups compared to control group.

\section{b.}
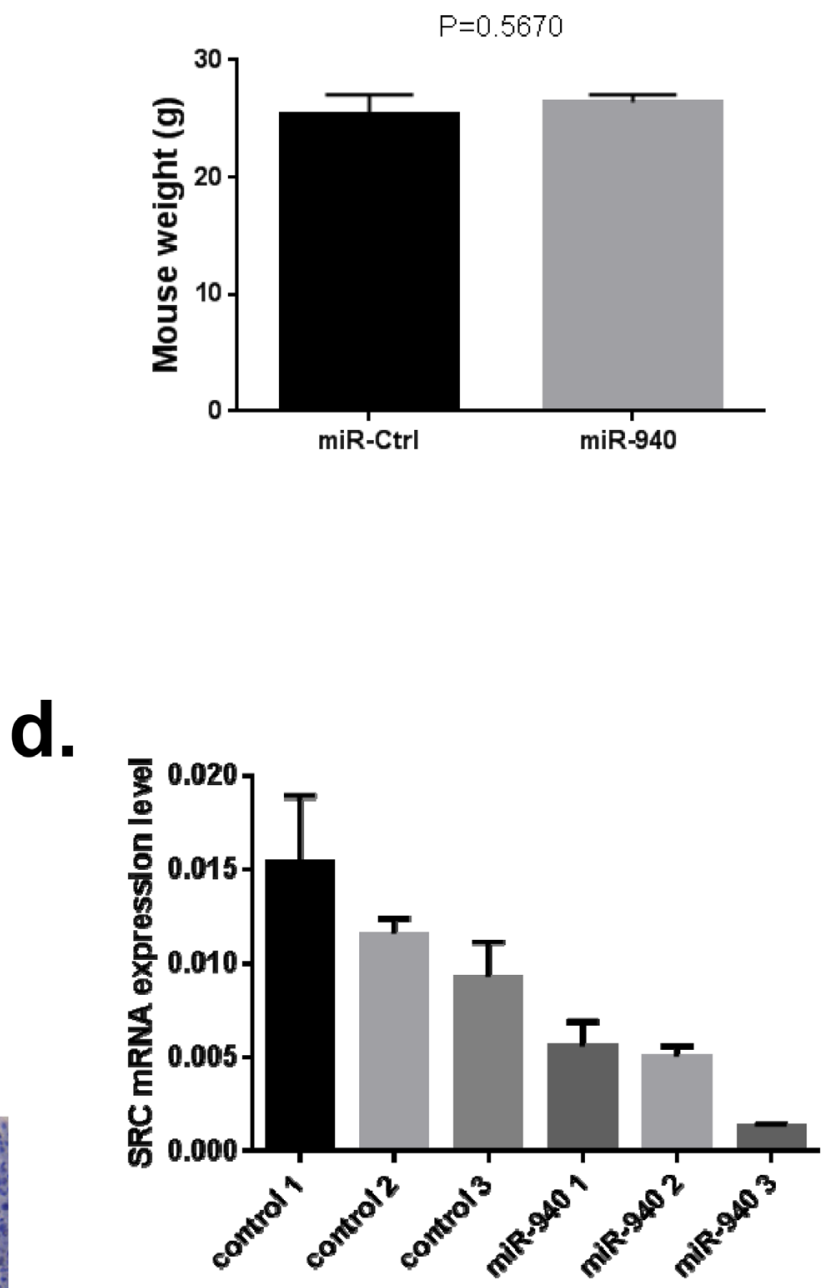

Figure 7: Overexpression of miRNA-940 significantly inhibits tumor growth in vivo. a. The tumor weight of the miR-940 group $(\mathrm{g})$ measured at the end of the experiment were significantly decreased compared to the control group $(P$-values obtained with Student's $t$-test; $* P<0.05$; compared with control miRNA treated group; bars and error bars represent mean values and the corresponding SE. b. Body weight in HeyA8 orthotopic mouse model of OC. No unwanted effects in terms of change in mouse body weight at the end of animal study. c. Immunohistochemical staining for tumor proliferation (Ki67) in the HeyA8 orthotopic murine model of ovarian cancer. Quantification of Ki67 positive cells in Control miRNA and miR-940 treated groups were determined from 10 randomly selected fields in a single sample. Two independent reviewers were blinded to the grouping when measuring the percentages of Ki-67-positive cells. The data are shown as mean $\pm \mathrm{SE}(\mathrm{n}=10 ; * * * \mathrm{P}<0.001$ (Student's t-test).vs. control group. d. Src protein expression were analyzed using protein lysates obtained from tumors. Src protein levels were lower in groups treated with miR-940 compared to CTL-miRNA. 


\section{SRC is involved in miR-940-mediated suppression of $\mathrm{OC}$ cells tumorgenesis}

To investigate whether the regulatory effects of miR-940 on the proliferation, invasion and migration of OC cells are mediated by SRC, we applied siRNAmediated SRC inhibition method to analyze whether it could replicated the tumor suppressor of miR-940 in OC cell lines. SiRNA-mediated suppression of SRC and its downstream genes was confirmed by Western blot analysis (Figure 8a). As Expected, SRC knockdown significantly inhibited colony formation ability (Figure $8 b)$. Similarly, SRC knockdown suppressed cell invasion and migration of OC cells (Figure 8c, 8d, respectively). These results were similar to the effects of miR-940 overexpression.

\section{Neutral sphingomyelinase 2 inhibitor (GW4869) reduces exosome secretion and exocytosis of miR-940}

Emerging evidence suggests that the secretion of miRNAs in exosomes is dependent on ceramide via its production by neutral sphingomyelinase 2 (nSMase 2 ) $[43,44]$. Inhibition of de novo ceramide synthesis by treatment with an nSMase inhibitor impaired exosomal miRNA release, apparently due to decreased formation of miRNA-containing exosomes $[45,46]$. To determine the effect of nSMase inhibitor, GW4869 on exosomal miR940 secretion in OC cells, we treated both HeyA8 and SKOV3IP1 cell lines with GW4869 or dimethylsulfoxide vehicle for $24 \mathrm{~h}$. GW4869 treatment significantly reduced the number of vesicles present in exosomes as detected a.

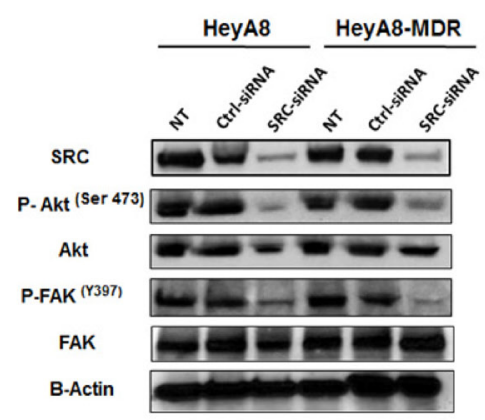

c.

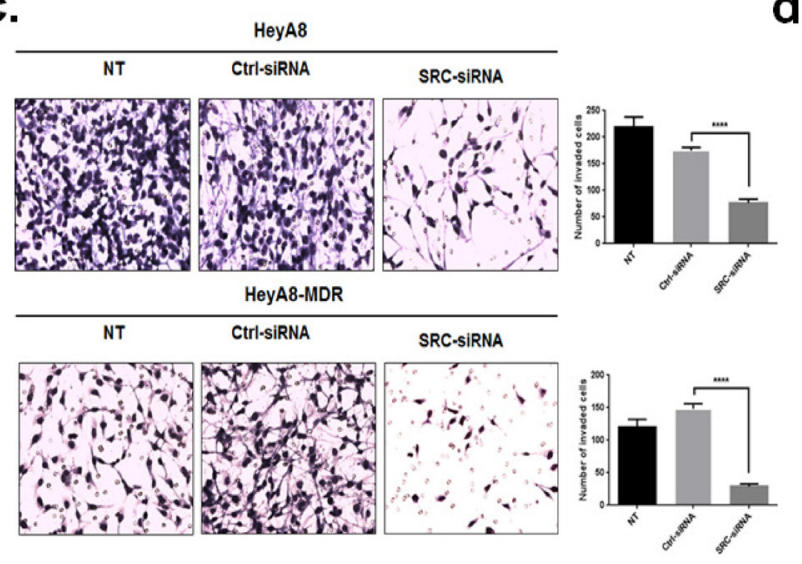

b.
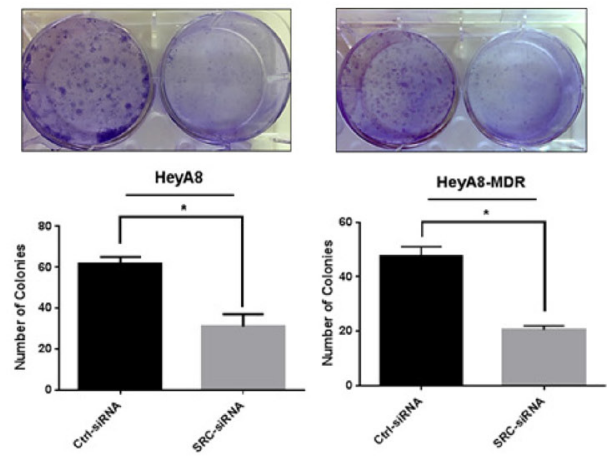

d.

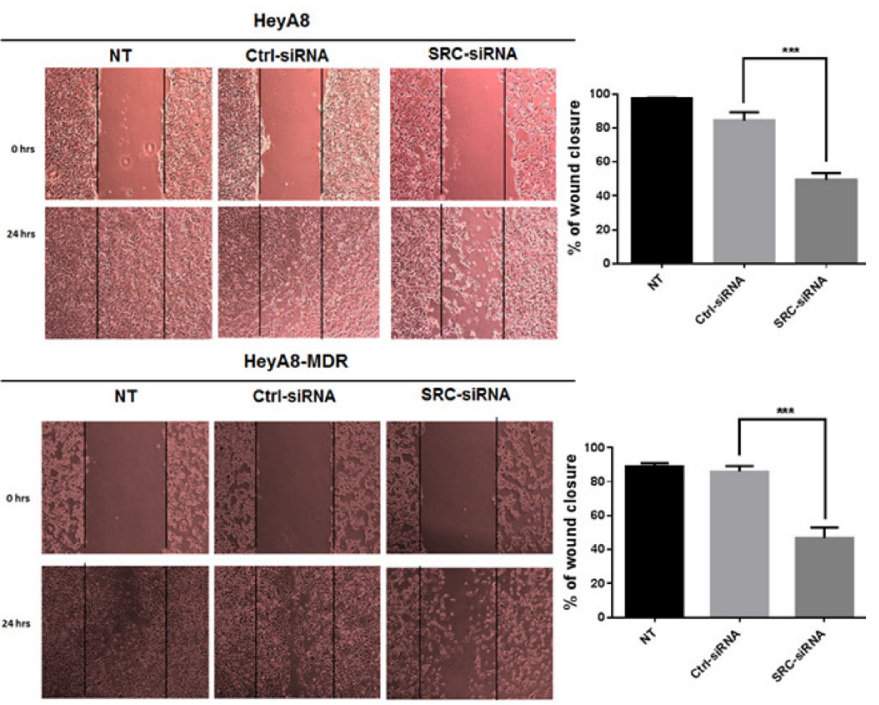

Figure 8: Knockdown of SRC inhibited OC cell proliferation, migration and invasion in vitro. a. Expression of SRC and its downstream genes in HeyA8 andHeyA8. MDR cells transfected with SRC-siRNA or control siRNA (Ctl-siRNA) was detected by Western blot. b. Colony formation assay was used to detect the effects on cell proliferation of HeyA8 and HeyA. MDR cells transfected with SRC siRNA. Downregulation of SRC decreased colony formation ability $(* p<0.05)$. The experiment was repeated three times. $\mathbf{c}$ and $\mathbf{d}$. Downregulation of SRC decreased cell invasion and migration ability. The images shown are representative images from three independent experiments, and a statistical analysis was performed (mean $\pm \mathrm{SE} ; * * * \mathrm{p}<0.001 ; * * * P<0.0001$ ) vs. control group. 
by NTA (Figure 9a, 9b). Inhibition of nSMase caused a threefold increase in intracellular levels of miR-940 in in treated groups than vehicle control groups (Figure 9c, 9d).

Furthermore, treatment of ovarian cancer cells with GW4886 led to decrease in cancer cell invasion and migration (Supplementary Figure 7a and $7 \mathrm{~b}$ ). We also checked p-SRC levels by western blotting, as well as major apoptosis markers. p-SRC levels, as well as major apoptosis markers such as pro-caspase 3 and 9 were dramatically decreased by GW4886 treatment (Supplementary Figure 7c).

\section{DISCUSSION}

In the present study, we found that miR-940 is highly expressed in exosomes derived from cancer cells, while not in exosomes from normal cells. Thus, the incorporation of miR-940 in exosomes may represent a characteristic of cancer cells not found in normal cells. We also found that ectopic expression of miR-940 resulted in antitumor activity and decreased tumor cell proliferation in vivo and in vitro. This findings may suggest an exclusionary mechanism used by cancer cells to down regulate tumor suppressor miRNAs. A previous study showed that the let-

\section{a.}

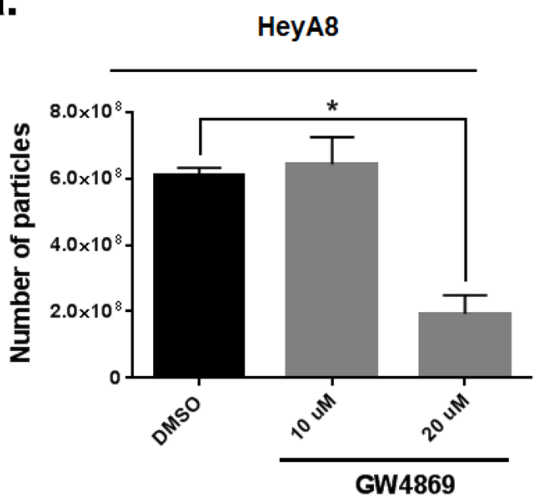

c.

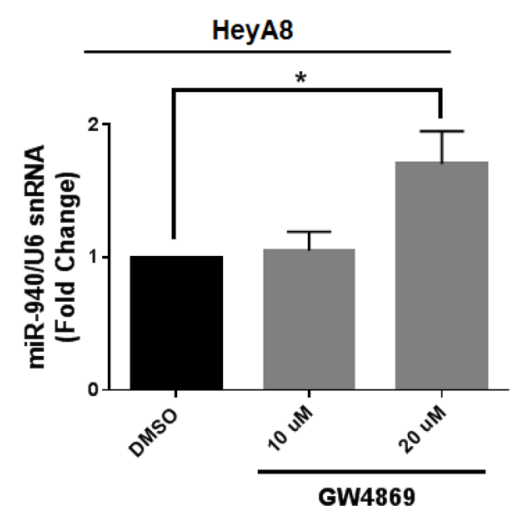

7 miRNA family is abundant in two OC cell exosomes and suggested that the release of exosomes and miRNA content of exosomes significantly differ between OC cell lines and correlate with their invasive potential [47]. In our recent study, we also showed that both resistant and sensitive ovarian cancer cells release miR-6126; a tumor suppressor targeting integrin beta-1 via their exosomes [48]. Ohshima and colleagues suggested that metastatic gastric cancer cells release let-7 miRNAs into the extracellular environment via exosomes to maintain their oncogenesis [49]. Another recent study showed that metastatic cells from bladder carcinoma discard via exosomes the tumor suppressor miRNAs that restrict their metastatic progression [50]. All these observations are in line with the data obtained in our study.

Exosomal miRNAs also function as mediators of cell-cell communication, which may lead to cancer cell growth, migration, invasion, dissemination, and metastasis or the impairment of the immune system response [5153]. Our findings indicate that cancer cells, use exosomes for intercellular communication and to discard tumor suppressor miRNAs to maintain an endogenous balance between tumor suppressor miRNAs and their oncogenic targets.

b.

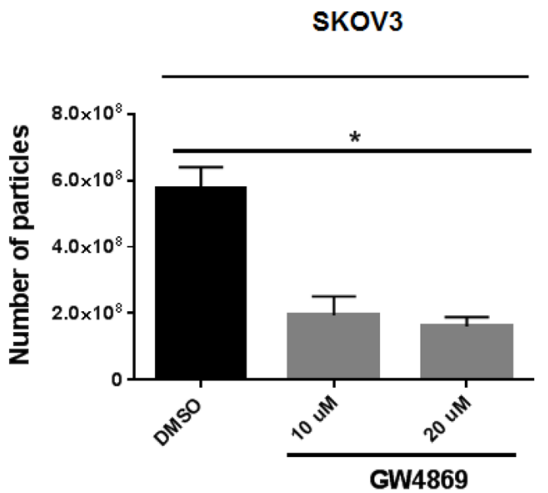

d.

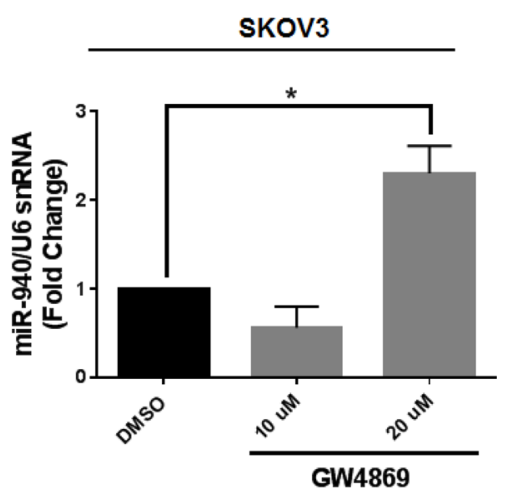

Figure 9: Neutral sphingomyelinase 2 inhibitor (GW4869) reduces exosomal miR-940 secretion in OC cells. a and b. Quantification of exosomes by Nanoparticle Tracking Analysis. Data are presented as mean \pm SE. *, p $<0.05$. (Student t-test). The experiment was repeated two times. $\mathbf{c}$ and $\mathbf{d}$. Inhibition of nSMase caused a significant increase in intracellular levels of miR-940 in in treated groups. The data are shown as mean \pm . SE of two separate experiments. ${ }^{*} \mathrm{P}<0.051$ indicates significant difference compared with vehicle control groups. 
To date, several studies described the role of miR940 in different types of cancers including breast cancer [54], hepatocellular carcinoma [55], nasopharyngeal carcinoma [56], pancreatic ductal adenocarcinoma [57], and prostate cancer [58]. It was reported in many studies that miR-940 was highly expressed in normal tissues compared with tumors, and miR-940 was shown to inhibit the migratory and invasive potential of cancer cells by suppressing CXCR2 [59], MIEN1 [58], MyD88 [57], Nestin [56], and ZNF24 [54]. Moreover, the EstrogenRelated Receptor Gamma (ESRRG) was targeted by miR940, and suppression of ESRRG inhibited hepatocellular carcinoma cell lines growth and induced cell apoptosis. The knockdown of miR-940 restored MKP1 and MKK4 expression and attenuated cisplatin resistance in lung cancer. Paradoxically, miR-940 has been demonstrated to promote tumor cell invasion and metastasis by downregulating GSK3 $\beta /$ sFRP1 [60] and ZNF24 in gastric cancer [61], respectively. However, the clinical significance of miR-940 and the biological roles of miR940 and its direct functional targets in OC has not yet been evaluated. A key observation in this study is the regulation of SRC by miR-940 administration, exerting a tumor suppressor effect in both in vivo and in vitro. The SRC proto-oncogene is a non-receptor tyrosine kinase that is involved in a variety of cellular functions including cell proliferation, invasion, migration, and apoptosis [62]. Src kinases have been reported to be overexpressed and activated in a high proportion of ovarian cancers [63].

Inhibition of neutral sphingomyelinase 2 (nSMase 2), either by small inhibitor or siRNA have been found previously to regulate secretion of exosomes [43, 64, 65]. In the present study, we used GW4869, which is an nSMase2 inhibitor, to confirm that intracellular miR940 down-regulation is an exosome-dependent process. Results showed that miR-940 accumulated in cells following the inhibition of exosome membrane formation by GW4869.

Several studies have concentrated on miRNA signatures of exosomes derived from cancer cells such as ovarian, breast, pancreatic, prostate, and others [18, 66-69], but few have assessed the function of these miRNAs. Furthermore, exploration of the effects of the released miRNAs on the microenvironment of various types of cancer cells may elucidate potential homeostatic regulation at this level.

Taken together, our findings shed light on how OC cells use exosomal pathways as a mechanism whereby cells rapidly discard specific tumor-suppressor conforming the hypothesis that malignant cells may release their tumor-suppressor miRNAs via exosomes into the extracellular environment to maintain and promote tumorigenesis at the intracellular level. The release of miR-940-rich exosomes may represent a new and additional layer of regulation of miR-940 expression levels and, in turn, of the SRC mRNA that is targeted by this miRNA and critically control OC progression.

\section{MATERIALS AND METHODS}

\section{Cell lines and culture conditions}

The human epithelial OC cell lines were obtained from American Type Culture Collection (Manassas, VA). HeyA8, SKOV3IP1, A2780-PAR, and A2780-CP20 and the non-transformed human ovarian surface epithelial cell line HIO-180 were maintained as described previously [70-72]. The taxane-resistant cell lines HeyA8-MDR and SKOV3-TR were maintained in Roswell Park Memorial Institute 1640 (RPMI 1640) medium (Life Technologies) supplemented with $15 \%$ fetal bovine serum (FBS) and 1\% penicillin/streptomycin with paclitaxel (300 $\mathrm{ng} \mathrm{ml}^{-1}$ for HeyA8-MDR; $150 \mathrm{ng} \mathrm{ml}^{-1}$ for SKOV3-TR). The A2780CP20 cell line was developed by sequential exposure of the A2780 cell line to increasing concentrations of cisplatin. HEK293 (human embryonic kidney) cells were maintained in Dulbecco's modified Eagle medium (Life Technologies) supplemented with 10\% FBS and $1 \%$ penicillin/streptomycin. In addition, cell lines were routinely tested to confirm the absence of Mycoplasma, and all experiments were performed with cultures at 60 $70 \%$ confluence.

\section{Exosome isolation from cell media}

Exosomes are traditionally isolated from conditioned media by serial centrifugation at a low speed, followed by ultracentrifugation at $100,000 \times g$ to pellet the exosomes $[73,74]$. Recently, a proprietary method of exosome isolation was made commercially available and was reported to provide a rapid and efficient method for exosome isolation $[23,75,76]$. Briefly, cells were cultured for 48 hours; thereafter, media were replaced with RPMI 1640 supplemented with $10 \%$ exosome-depleted FBS [77]. (EXO-FBS-250 A-1, System Biosciences). After 24 hours, cells and debris were removed by centrifugation at $350 \mathrm{~g}$ for 10 minutes and $2000 \mathrm{~g}$ for 30 minutes. This was followed by filtration of the supernatant with 0.2 $\mu \mathrm{m}$ filters. Next, each sample was combined with $1 / 2^{\text {th }}$ volume of total exosome isolation reagent (Invitrogen, Life Technologies). Cell medium and the exosome isolation reagent were mixed by brief vortexing until a homogeneous solution was formed and incubated at $4{ }^{\circ} \mathrm{C}$ overnight before centrifugation at $4^{\circ} \mathrm{C}$ at $10,000 \mathrm{~g}$ for 1 hour. The supernatant was aspirated and discarded, and the exosome pellet was resuspended in phosphate-buffered saline (PBS) and stored at $-20^{\circ} \mathrm{C}$ until further use.

\section{Atomic force microscopy}

For atomic force microscopy (AFM) imaging of isolated exosomes, samples were diluted 1:100 in deionized water and adsorbed to freshly cleaved mica sheets for 10 minutes. The sheets were rinsed thoroughly with deionized water to remove unbound exosomes and 
dried under a gentle stream of nitrogen. A Bioscope II (Veeco Digital Instruments, Santa Barbara, CA) was used for tapping mode AFM imaging using silicon probes with spring constant $k=305 \mathrm{KHz}$ (OTESPA, Veeco). Topographic height and phase images were recorded simultaneously at $512 \times 512$ pixels at a scan rate of 0.4 $\mathrm{Hz}$. The height of the exosomes was obtained from a line profile of height images (Nanoscope software). Image processing was performed using the free WSxM software (Nanotec, Spain).

\section{Nanoparticle tracking analysis}

Isolated exosomes were suspended in $200 \mu \mathrm{l}$ of PBS. We obtained $5 \mu \mathrm{l}$ of this sample, diluted it 1:100 in $1 \mathrm{x}$ PBS, and analyzed it using a NanoSight LM10 instrument, following the manufacturer's protocol (NanoSight Ltd., Amesbury, UK). Exosomes were illuminated by the laser, and their movement under Brownian motion was recorded in videos. The nanoparticle tracking analysis (NTA) software uses the video data for tracking the Brownian motion of individual vesicles and thereby calculating their size and total concentration. All samples were evaluated in triplicate.

\section{Western blot analysis}

Cells and exosomes were lysed in1X RIPA buffer (Thermo Scientific) containing protease and phosphatase inhibitors. Lysates were centrifuged, supernatants were collected, and the total protein concentration in lysates was assessed using the BCA protein assay kit (Pierce Biotechnology). Subsequently, lysates were resuspended in Laemmli loading buffer (Bio-Rad) and heated at $95^{\circ} \mathrm{C}$ for 5 minutes. Next, Western blotting was performed as previously reported $[78,79]$. All antibodies used in this study are listed in Supplementary Table 1.

\section{RNA isolation}

Cellular and exosomal RNA were isolated using the miRCURY RNA Isolation Kit (Exiqon) according to the manufacturer's protocol and as described previously [80, 81]. Eldh and colleagues demonstrated that, for both cells and exosomes, the miRCURY pure column-based method showed the highest total RNA yield and the broadest RNA size distribution when compared with 6 other RNA isolation methods [82]. The quantity and quality of the RNA extractions were determined using an Agilent 2100 Bioanalyzer with the RNA 6000 Nano or RNA 6000 Pico Kit according to the manufacturer's protocol (Agilent Technologies).

\section{miRNA microarray expression analysis}

For miRNA expression analysis, we used a GeneChip 4.0 miRNA microarray (Affymetrix), which covers all of the 2,578 mature human miRNAs available in miRBase version 20 (www.mirbase.org/). Hybridization and scanning of the samples were performed by the Noncoding RNA Program at MD Anderson's Center for Targeted Therapy. Briefly, $600 \mathrm{ng}$ of total RNA of each sample was subjected to a tailing reaction labeled with the FlashTag Biotin HSR RNA Labeling Kit (Affymetrix) followed by ligation of the biotinylated signal molecule to the target RNA sample according to the manufacturer's instructions. Each sample was then hybridized to a GeneChip 4.0 miRNA array at $48^{\circ} \mathrm{C}$ for 16 hours in the GeneChip Hybridization Oven 645 and rotated at $60 \mathrm{rpm}$. Immediately following hybridization, the probe array underwent an automated washing and staining protocol on the GeneChip Fluidics Station 450. Once the probe array was hybridized, washed, and stained, it was scanned using a GeneChip Scanner 3000 7G. The expression values were summarized and normalized with the robust multichip analysis program Affymetrix Expression Console 1.3. AffymetrixTranscriptome Analysis Console software was used for additional statistical analysis. Differentially expressed miRNAs were identified by using one-way analysis of variance (ANOVA) with p- values cutoff by 0.05 and fold change more than 2.0 or less than -2 .

\section{Quantitative real-time polymerase chain reaction}

For mRNA quantification, cDNA was synthesized from $1 \mu \mathrm{g}$ of isolated RNA using a QuantiTect Reverse Transcription Kit (Qiagen) according to the manufacturer's instructions. Quantitative real-time polymerase chain reaction (qRT-PCR) was carried out with BX-384 BioRad using the QuantiTect SYBR Green PCR kit (Qiagen) according to the manufacturer's protocol. To quantify miRNAs, $1 \mu \mathrm{g}$ of total RNA was reverse transcribed with a qScript miRNA cDNA Synthesis Kit (Quanta Biosciences), and qRT-PCR was carried out using PerfeCta SYBR Green SuperMix (Quanta Biosciences). All reactions were performed in triplicate. Relative quantification of mRNA and miRNA expression was calculated with the $2-\Delta \Delta \mathrm{Ct}$ method. Transcript values were normalized to those obtained from the amplification of the internal control (glyceraldehyde 3-phosphate dehydrogenase) for mRNAs and U6 snRNA for intracellular and extracellular miRNAs. All miRNA Assay Primers used in this study were purchased commercially (Quanta Biosciences or Qiagen), and are based on human miRNA and snRNA sequences.

\section{In vitro miRNA and siRNA transfection}

Cells were seeded at $1 \times 10^{5}$ per well in 6-well plates and allowed to attach for at least 16 hours. The mirvana miRNA mimic of microRNA-940 mimic (miR-940) or small interfering RNA (siRNA) targeting $\mathrm{SRC}$, and their negative controls were transfected 
using HiPerFect transfection reagent (Qiagen) (at a final concentration of $50 \mathrm{nM}$ ) for 72 hours. Media were changed 6 hours following transfections to minimize toxicity. All the siRNAs were obtained from Sigma and miRNAs were obtained from Life Technologies. All the oligonucleotide sequences are listed in Supplementary Table 2. All the siRNAs were obtained from Sigma and miRNAs were obtained from Life Technologies. MiRVana miRNA mimic negative control \#1 (catalogue number 4464061, ThermoFisher Scientific) was used as the negative control.

\section{Cell viability and proliferation assays}

The viability of cells was detected by 3-(4,5-dimethylthiazol-2-yl)-5-(3-carboxy-methoxyphenyl)2-(4-sulfophenyl)-2H-tetrazolium (MTS) assay (Promega). Viable cells were seeded at a density of 1000 cells/well in 96-well plates and transfected with $50 \mathrm{nM}$ control or miR-940 mimics for 48 hours. After treatment, a solution containing MTS and phenazinemethosulfate $(20: 1 \mathrm{v} / \mathrm{v})$ was added to the cells for $1-3$ hours at $37^{\circ} \mathrm{C}$, and the viable growing cells were estimated by monitoring the absorption of the product at $490 \mathrm{~nm}$, based on the generation of formazan in live cells. All experiments were performed in 6 replicates, and the results were reported as the mean absorption \pm standard deviation.

\section{Matrigel invasion assay}

The invasiveness of HeyA8, HeyA8-MDR, and SKOV3IP1 cells was determined as previously described [83]. Briefly, cells were treated with $50 \mathrm{nM}$ of the indicated oligonucleotide, and 48 hours later, live cells were collected and washed with serum-free media. Fixed numbers of the viable cells $\left(4 \times 10^{5}\right.$ cells $)$, were resuspended in $1 \mathrm{~mL}$ of serum-free RPMI-1640 medium and added onto 6 -well plate Transwell inserts $(8-\mu \mathrm{m}$-pore size; Fisher Scientific) coated with a Matrigel basement membrane $(0.7 \mathrm{mg} / \mathrm{mL}$; BD Biosciences $)$. Lower chambers were filled with $2 \mathrm{~mL}$ of medium supplemented with $15 \%$ FBS. After 24 hours, non-invading cells on the upper surface of the filter were removed with cotton swabs. Cells that invaded through the Matrigel onto the lower side of the filter were fixed, stained with the Hema3 Stain System (Fisher Scientific), and photographed. The number of cells that invaded the lower side of the filter was counted in 5 fields and expressed as the mean number of cells from triplicate measurements.

\section{Wound-healing assay}

Ovarian cancer cells were seeded in 6-well plates $\left(1 \times 10^{5}\right.$ cells $)$ and cultured to form a confluent monolayer. Cells were transfected with $50 \mathrm{nM}$ of the indicated oligonucleotide for 48 hours. Wounds were then carefully made on the cell layer using $10 \mu \mathrm{l}$ sterile micropipette tips, and cells were washed several times with appropriate culture medium to remove cell debris. Immediately after scratches were made, the cells were photographed using a phase-contrast microscope (Nikon Instruments Inc.), to determine the wound width at 0 hours. The cultures were continued, and the cells were photographed again after 12 hours and after 24 hours of wounding the cell layer. The wound healing was visualized by comparing photographs taken at 0 hours with those taken 12 and 24 hours later. At least 5 random non-overlapping images per experiment were analyzed and quantitated using Image $\mathbf{J}$ software (National Institutes of Health, Bethesda, MD). Three experiments were done in duplicate.

\section{Colony formation assay}

Cells were seeded in 6-well plates at a low density (1000 cells/plate), transfected with miRNA or siRNA and their respective negative controls, and allowed to grow until visible colonies appeared. Then, the formed colonies were stained with crystal violet and counted. Each experiment was performed in duplicate.

\section{Flow cytometry analysis of cell-cycle}

Cells were transfected as previously described with miRNA mimics. Samples were washed in PBS and fixed in $75 \%$ ethanol overnight. Cells were then centrifuged and reconstituted in PBS containing $50 \mu \mathrm{g} /$ $\mathrm{mL}$ propidium iodide (PI) and $100 \mathrm{U} / \mathrm{mL}$ of RNAse A. Cells were incubated at $37^{\circ} \mathrm{C}$ for 30 minutes in the dark before flow cytometry analysis. CellQuest Pro software (BD Biosciences) was used to determine the number of cells in each phase of the cell cycle.

\section{Apoptosis}

Cell apoptosis was assessed by Annexin V/PI staining using an FITC apoptosis detection kit (BD Biosciences) according to the manufacturer's protocol. Apoptotic cells were analyzed with a FACSCalibur flow cytometer (BD Biosciences). CellQuest Pro software (BD Biosciences) was used to determine the number of apoptotic cells. Apoptosis was also assessed by monitoring the cleavage of caspase- 3 , caspase- 9 , and poly ADP ribose polymerase (PARP) via Western blotting.

\section{Luciferase reporter assay}

Luciferase reporter plasmids containing fragments of the wild-type 3'UTR (CS-HmiT064432-MT06-02 and CS-HmiT064432-MT06-03) and the mutated 3'UTR (CSHmiT064432-MT06-02a and CS-HmiT064432-MT0603a) miR-940 binding site of SRC (NM_198291) were specifically obtained from Genecopoeia (Rockville, MD). Luciferase activity assays were performed following the manufacturer's protocols. Briefly, HEK293 cells 
were seeded in 6-well plates and co-transfected with the luciferase constructs and miR-940 or miR-Control using Lipofectamin 2000 (Invitrogen). The cells were transferred to a 96-well plate 24 hours after transfection and cultured for another 24 hours. Luciferase activity was measured using a Dual-Luciferase Reporter Assay according to the manufacturer's instructions (Genecopoeia). Results represent three independent experiments, and each was performed in triplicate.

\section{Inhibition of exosome release}

To validate whether miR-940 disposal depends on exosome transfer, exosome release was blocked using GW4869 (D1692; Sigma-Aldrich, USA), which is a specific chemical inhibitor for nSMase2. HeyA8 and SKOV3IP1 cells were pre-seeded in a T25 flask and cultured for $24 \mathrm{~h}$ in complete medium. After the incubation, the medium was switched to fresh exosome free medium with different GW4869 concentrations. The cells were collected, and exosome fraction was obtained from the culture medium after 24-h incubation.

\section{Orthotopic in vivo model}

To generate tumors, $2.5 \times 10^{5}$ HeyA 8 cells were injected into the peritoneal cavity of 8- to 12-week-old female athymic nude mice (Frederick Cancer Research and Development Center, Frederick, MD). The mice were cared for in accordance with guidelines set forth by the American Association for Accreditation of Laboratory Animal Care and the United States Public Health Service Policy on Human Care and Use of Laboratory Animals. All mouse studies were approved and supervised by the MD Anderson Institutional Animal Care and Use Committee. One week after tumor cell injection, mice were randomly assigned to receive miR-control or miR-940 intravenously (10 mice per group). All miRNAs for in vivo delivery were incorporated into 1, 2-dioleoyl-sn-glycero-3phosphatidylcholine (DOPC) nanoliposomes as previously described [3]. All groups received twice-weekly miRNA treatments for 4 weeks. When treatment was completed, the mice were euthanized. After euthanasia, mouse and tumor weight, the number of nodules, and the distribution of tumors were recorded. Tumor tissues were fixed in formalin and embedded in paraffin or were snap-frozen in liquid nitrogen for immunohistochemical analysis.

\section{Immunohistochemical analysis}

The immunohistochemical analysis for tumors cell proliferation was performed as previously described [79, $83,84]$. The antibodies used and the vendors are listed in Supplementary Table 1.

\section{Survival analysis}

We downloaded miRNA-Seq Level3 data publicly available from the Cancer Genome Atlas Project (TCGA; http://tcga-data.nci.nih.gov/, additional file 5) for miR940 in patients with ovarian serous cystadenocarcinoma $(\mathrm{OV})$. For the miRNA-Seq data, we derived the 'reads per_million_miRNA_mapped' values for the mature form MIMATT0004983 from the 'isoform_quantification' files. Patient overall survival information was retrieved from cbioPortal (http://www.cbioportal.org/). The analyses were carried out in $\mathrm{R}$ statistical environment (version 3.0.1) (http:///www.r-project.org/). All the tests were two-sided and considered statistically significant at the 0.05 level. For miR-940, the tumor samples were dichotomized into high and low miRNA expression groups at percentile cutoffs between 0.25 and 0.75 with a step of 0.01 . We tested whether a log-rank test applied at any cut-point would yield a nominal $P$ value $<0.05$. The optimal cutoff percentile (as determined by the lowest $\mathrm{P}$ value) was identified for miR-940 as 0.58 (range for low expression $=0.689-4.339$, and for high expression $=4.343-7.317(\log 2)$. The Kaplan-Meier plots were generated for high and low miR-940. The numbers of patients at risk in each group at different time points are presented at the bottom of the graph. A table with patients overall survival and miRNA expression is provided in the supplementary material.

\section{Statistical analysis}

Unless specified otherwise, the data are expressed as the mean \pm standard error of three independent experiments. Statistical analysis was performed using the Student's $t$ test to determine statistical significance, and $P$ values indicate the probability of the means compared, being equal with $* P<0.05$, **P $<0.01, * * * P<0.001$, and $* * * * P<0.0001$. Student's $t$-tests and ANOVA were calculated with GraphPad software.

\section{ACKNOWLEDGMENTS}

This study was funded by the NIH Common Fund (UH2TR000943), through the Office of Strategic Coordination/Office of the NIH Director and MD Anderson's Cancer Center Support Grant (CCSG) (grant number is CA016672); Ministry of High Education, Cultural affairs and Mission Sector, Joint-Supervision Program, Egypt; and The RNA Center, MD Anderson Cancer Center. We thank Ana Maria Zaske for AFM imaging at IM Bioscope II - UT Core Facility at the Internal Medicine Department, University of Texas Health Science Center at Houston. 


\section{CONFLICTS OF INTEREST}

The authors declare that they have no conflicts of interests.

\section{REFERENCES}

1. Siegel RL, Miller KD, Jemal A. Cancer statistics, 2015. CA Cancer J Clin. 2015; 65:5-29.

2. Yap TA, Carden CP, Kaye SB. Beyond chemotherapy: targeted therapies in ovarian cancer. Nat Rev Cancer. 2009; 9:167-181.

3. Sun Y, Hu L, Zheng H, Bagnoli M, Guo Y, Rupaimoole R, Rodriguez-Aguayo C, Lopez-Berestein G, Ji P, Chen K, Sood AK, Mezzanzanica D, Liu J, et al. MiR-506 inhibits multiple targets in the epithelial-to-mesenchymal transition network and is associated with good prognosis in epithelial ovarian cancer. J Pathol. 2015; 235:25-36.

4. Thery C, Zitvogel L, Amigorena S. Exosomes: composition, biogenesis and function. Nat Rev Immunol. 2002; 2:569-579.

5. Jenjaroenpun P, Kremenska Y, Nair VM, Kremenskoy M, Joseph B, Kurochkin IV. Characterization of RNA in exosomes secreted by human breast cancer cell lines using next-generation sequencing. PeerJ. 2013; 1:e201.

6. Gallo A, Tandon M, Alevizos I, Illei GG. The majority of microRNAs detectable in serum and saliva is concentrated in exosomes. PLoS One. 2012; 7:e30679.

7. Simpson RJ, Lim JW, Moritz RL, Mathivanan S. Exosomes: proteomic insights and diagnostic potential. Expert Rev Proteomics. 2009; 6:267-283.

8. Sato-Kuwabara Y, Melo SA, Soares FA, Calin GA. The fusion of two worlds: non-coding RNAs and extracellular vesicle - diagnostic and therapeutic implications (Review). Int J Oncol. 2015; 46:17-27.

9. Johnstone RM, Adam M, Hammond JR, Orr L, Turbide C. Vesicle formation during reticulocyte maturation. Association of plasma membrane activities with released vesicles (exosomes). J Biol Chem. 1987; 262:9412-9420.

10. Berindan-Neagoe I, Calin GA. Molecular pathways: microRNAs, cancer cells, and microenvironment. Clin Cancer Res. 2014; 20:6247-6253.

11. Zamore PD, Haley B. Ribo-gnome: the big world of small RNAs. Science. 2005; 309:1519-1524.

12. Nakano H, Yamada Y, Miyazawa T, Yoshida T. Gain-offunction microRNA screens identify miR-193a regulating proliferation and apoptosis in epithelial ovarian cancer cells. Int J Oncol. 2013; 42:1875-1882

13. Dykxhoorn DM, Wu Y, Xie H, Yu F, Lal A, Petrocca F, Martinvalet D, Song E, Lim B, Lieberman J. miR-200 enhances mouse breast cancer cell colonization to form distant metastases. PLoS One. 2009; 4:e7181.
14. Pecot CV, Rupaimoole R, Yang D, Akbani R, Ivan C, Lu C, Wu S, Han HD, Shah MY, Rodriguez-Aguayo C, BottsfordMiller J, Liu Y, Kim SB, et al. Tumour angiogenesis regulation by the miR-200 family. Nat Commun. 2013; 4:2427.

15. Valadi H, Ekstrom K, Bossios A, Sjostrand M, Lee JJ, Lotvall JO. Exosome-mediated transfer of mRNAs and microRNAs is a novel mechanism of genetic exchange between cells. Nat Cell Biol. 2007; 9:654-659.

16. Mittelbrunn M, Gutierrez-Vazquez C, Villarroya-Beltri C, Gonzalez S, Sanchez-Cabo F, Gonzalez MA, Bernad A, Sanchez-Madrid F. Unidirectional transfer of microRNAloaded exosomes from $\mathrm{T}$ cells to antigen-presenting cells. Nat Commun. 2011; 2:282.

17. Kosaka N, Iguchi H, Yoshioka Y, Hagiwara K, Takeshita F, Ochiya T. Competitive interactions of cancer cells and normal cells via secretory microRNAs. J Biol Chem. 2012; 287:1397-1405.

18. Taylor DD, Gercel-Taylor C. MicroRNA signatures of tumor-derived exosomes as diagnostic biomarkers of ovarian cancer. Gynecol Oncol. 2008; 110:13-21.

19. Resnick KE, Alder H, Hagan JP, Richardson DL, Croce CM, Cohn DE. The detection of differentially expressed microRNAs from the serum of ovarian cancer patients using a novel real-time PCR platform. Gynecol Oncol. 2009; 112:55-59.

20. Hausler SF, Keller A, Chandran PA, Ziegler K, Zipp K, Heuer S, Krockenberger M, Engel JB, Honig A, Scheffler M, Dietl J, Wischhusen J. Whole blood-derived miRNA profiles as potential new tools for ovarian cancer screening. Br J Cancer. 2010; 103:693-700.

21. Chung YW, Bae HS, Song JY, Lee JK, Lee NW, Kim T, Lee KW. Detection of microRNA as novel biomarkers of epithelial ovarian cancer from the serum of ovarian cancer patients. Int J Gynecol Cancer. 2013; 23:673-679.

22. Shapira I, Oswald M, Lovecchio J, Khalili H, Menzin A, Whyte J, Dos Santos L, Liang S, Bhuiya T, Keogh M, Mason C, Sultan K, Budman D, et al. Circulating biomarkers for detection of ovarian cancer and predicting cancer outcomes. Br J Cancer. 2014; 110:976-983.

23. Schageman J, Zeringer E, Li M, Barta T, Lea $K$, $\mathrm{Gu}$ J, Magdaleno S, Setterquist R, Vlassov AV. The complete exosome workflow solution: from isolation to characterization of RNA cargo. Biomed Res Int. 2013; 2013:253957.

24. Zeringer E, Li M, Barta T, Schageman J, Pedersen KW, Neurauter A, Magdaleno S, Setterquist R, Vlassov AV. Methods for the extraction and RNA profiling of exosomes. World J Methodol. 2013; 3:11-18.

25. Wang J, Wang Z, Mo Y, Zeng Z, Wei P, Li T. Effect of hyperthermic CO-treated dendritic cell-derived exosomes on the human gastric cancer AGS cell line. Oncol Lett. $2015 ; 10: 71-76$. 
26. Sharma S, Rasool HI, Palanisamy V, Mathisen C, Schmidt M, Wong DT, Gimzewski JK. Structural-mechanical characterization of nanoparticle exosomes in human saliva, using correlative AFM, FESEM, and force spectroscopy. ACS Nano. 2010; 4:1921-1926.

27. Kharaziha P, Ceder S, Li Q, Panaretakis T. Tumor cellderived exosomes: a message in a bottle. Biochim Biophys Acta. 2012; 1826:103-111.

28. Rabinowits G, Gercel-Taylor C, Day JM, Taylor DD, Kloecker GH. Exosomal microRNA: a diagnostic marker for lung cancer. Clin Lung Cancer. 2009; 10:42-46.

29. Ekstrom K, Valadi H, Sjostrand M, Malmhall C, Bossios A, Eldh M, Lotvall J. Characterization of mRNA and microRNA in human mast cell-derived exosomes and their transfer to other mast cells and blood CD34 progenitor cells. J Extracell Vesicles. 2012; 1.

30. Hessvik NP, Phuyal S, Brech A, Sandvig K, Llorente A. Profiling of microRNAs in exosomes released from PC-3 prostate cancer cells. Biochim Biophys Acta. 2012; 1819:1154-1163.

31. Reczko M, Maragkakis M, Alexiou P, Grosse I, Hatzigeorgiou AG. Functional microRNA targets in protein coding sequences. Bioinformatics. 2012; 28:771-776.

32. Shaw LM. Tumor cell invasion assays. Methods Mol Biol. 2005; 294:97-105.

33. Rodriguez LG, Wu X, Guan JL. Wound-healing assay. Methods Mol Biol. 2005; 294:23-29.

34. Lewis BP, Shih IH, Jones-Rhoades MW, Bartel DP, Burge CB. Prediction of mammalian microRNA targets. Cell. 2003; 115:787-798.

35. Maragkakis M, Reczko M, Simossis VA, Alexiou P, Papadopoulos GL, Dalamagas T, Giannopoulos G, Goumas G, Koukis E, Kourtis K, Vergoulis T, Koziris N, Sellis T, et al. DIANA-microT web server: elucidating microRNA functions through target prediction. Nucleic Acids Res. 2009; 37:W273-276.

36. Aligayer H, Boyd DD, Heiss MM, Abdalla EK, Curley SA, Gallick GE. Activation of Src kinase in primary colorectal carcinoma: an indicator of poor clinical prognosis. Cancer. 2002; 94:344-351.

37. Masaki T, Igarashi K, Tokuda M, Yukimasa S, Han F, Jin YJ, Li JQ, Yoneyama H, Uchida N, Fujita J, Yoshiji H, Watanabe S, Kurokohchi K, et al. pp60c-src activation in lung adenocarcinoma. Eur J Cancer. 2003; 39:1447-1455.

38. Je DW, O YM, Ji YG, Cho Y, Lee DH. The inhibition of SRC family kinase suppresses pancreatic cancer cell proliferation, migration, and invasion. Pancreas. 2014; 43:768-776.

39. Han LY, Landen CN, Trevino JG, Halder J, Lin YG, Kamat AA, Kim TJ, Merritt WM, Coleman RL, Gershenson DM, Shakespeare WC, Wang Y, Sundaramoorth R, et al. Antiangiogenic and antitumor effects of SRC inhibition in ovarian carcinoma. Cancer Res. 2006; 66:8633-8639.
40. Kim HS, Han HD, Armaiz-Pena GN, Stone RL, Nam EJ, Lee JW, Shahzad MM, Nick AM, Lee SJ, Roh JW, Nishimura M, Mangala LS, Bottsford-Miller J, et al. Functional roles of Src and Fgr in ovarian carcinoma. Clin Cancer Res. 2011; 17:1713-1721.

41. Armaiz-Pena GN, Allen JK, Cruz A, Stone RL, Nick AM, Lin YG, Han LY, Mangala LS, Villares GJ, Vivas-Mejia P, Rodriguez-Aguayo C, Nagaraja AS, Gharpure KM, et al. Src activation by beta-adrenoreceptors is a key switch for tumour metastasis. Nat Commun. 2013; 4:1403.

42. Scholzen T, Gerdes J. The Ki-67 protein: from the known and the unknown. J Cell Physiol. 2000; 182:311-322.

43. Kosaka N, Iguchi H, Hagiwara K, Yoshioka Y, Takeshita F, Ochiya T. Neutral sphingomyelinase 2 (nSMase2)dependent exosomal transfer of angiogenic microRNAs regulate cancer cell metastasis. J Biol Chem. 2013; 288:10849-10859.

44. Essandoh K, Yang L, Wang X, Huang W, Qin D, Hao J, Wang Y, Zingarelli B, Peng T, Fan GC. Blockade of exosome generation with GW4869 dampens the sepsisinduced inflammation and cardiac dysfunction. Biochim Biophys Acta. 2015; 1852:2362-2371.

45. Kosaka N, Iguchi H, Yoshioka Y, Takeshita F, Matsuki Y, Ochiya T. Secretory mechanisms and intercellular transfer of microRNAs in living cells. J Biol Chem. 2010; 285:17442-17452.

46. Singh R, Pochampally R, Watabe K, Lu Z, Mo YY. Exosome-mediated transfer of miR-10b promotes cell invasion in breast cancer. Mol Cancer. 2014; 13:256.

47. Kobayashi M, Salomon C, Tapia J, Illanes SE, Mitchell $\mathrm{MD}$, Rice GE. Ovarian cancer cell invasiveness is associated with discordant exosomal sequestration of Let-7 miRNA and miR-200. J Transl Med. 2014; 12:4.

48. Kanlikilicer P, Saber M, Bayraktar R, Mitra R, Ivan C, Aslan B, Zhang X, Filant J, Silva AM, Rodriguez-Aguayo C, Bayraktar E, Pichler M, Ozpolat B, et al. Ubiquitous release of exosomal tumor suppressor miR-6126 from ovarian cancer cells. Cancer research. 2016.

49. Ohshima K, Inoue K, Fujiwara A, Hatakeyama K, Kanto K, Watanabe Y, Muramatsu K, Fukuda Y, Ogura S, Yamaguchi $\mathrm{K}$, Mochizuki T. Let-7 microRNA family is selectively secreted into the extracellular environment via exosomes in a metastatic gastric cancer cell line. PLoS One. 2010; 5:e13247.

50. Ostenfeld MS, Jeppesen DK, Laurberg JR, Boysen AT, Bramsen JB, Primdal-Bengtson B, Hendrix A, Lamy P, Dagnaes-Hansen F, Rasmussen MH, Bui KH, Fristrup $\mathrm{N}$, Christensen EI, et al. Cellular disposal of miR23b by RAB27-dependent exosome release is linked to acquisition of metastatic properties. Cancer Res. 2014; 74:5758-5771.

51. $\mathrm{Mu} \mathrm{W}$, Rana S, Zoller M. Host matrix modulation by tumor exosomes promotes motility and invasiveness. Neoplasia. $2013 ; 15: 875-887$. 
52. Zhou W, Fong MY, Min Y, Somlo G, Liu L, Palomares MR, Yu Y, Chow A, O'Connor ST, Chin AR, Yen Y, Wang Y, Marcusson EG, et al. Cancer-secreted miR-105 destroys vascular endothelial barriers to promote metastasis. Cancer Cell. 2014; 25:501-515.

53. Falcone G, Felsani A, D'Agnano I. Signaling by exosomal microRNAs in cancer. J Exp Clin Cancer Res. 2015; 34:32.

54. Hou LM, Chen MS, Yang HW, Xing TY, Li JD, Li GW, Zhang LN, Deng SS, Hu JN, Zhao XB, Jiang J. MiR-940 Inhibited Cell Growth and Migration in Triple-Negative Breast Cancer. Med Sci Monitor. 2016; 22:3666-3672.

55. Yuan B, Liang YS, Wang DN, Luo FM. MiR-940 inhibits hepatocellular carcinoma growth and correlates with prognosis of hepatocellular carcinoma patients. Cancer Sci. 2015; 106:819-824.

56. Ma J, Sun F, Li C, Zhang Y, Xiao W, Li Z, Pan Q, Zeng H, Xiao G, Yao K, Hong A, An J. Depletion of intermediate filament protein Nestin, a target of microRNA-940, suppresses tumorigenesis by inducing spontaneous DNA damage accumulation in human nasopharyngeal carcinoma. Cell Death Dis. 2014; 5.

57. Song B, Zhang CX, Li G, Jin G, Liu C. MiR-940 Inhibited Pancreatic Ductal Adenocarcinoma Growth by Targeting MyD88. Cell Physiol Biochem. 2015; 35:1167-1177.

58. Rajendiran S, Parwani AV, Hare RJ, Dasgupta S, Roby RK, Vishwanatha JK. MicroRNA-940 suppresses prostate cancer migration and invasion by regulating MIEN1. Mol Cancer. 2014; 13.

59. Ding D, Zhang YD, Yang RJ, Wang X, Ji GW, Huo LQ, Shao ZC, Li XC. miR-940 Suppresses Tumor Cell Invasion and Migration via Regulation of CXCR2 in Hepatocellular Carcinoma. Biomed Res Int. 2016.

60. Yang HW, Liu GH, Liu YQ, Zhao HC, Yang Z, Zhao CL, Zhang XF, Ye H. Over-expression of microRNA-940 promotes cell proliferation by targeting GSK3beta and SFRP1 in human pancreatic carcinoma. Biomedicine \& pharmacotherapy. 2016; 83:593-601.

61. Liu XY, Ge XX, Zhang Z, Zhang XW, Chang JJ, Wu Z, Tang WB, Gan L, Sun MH, Li J. MicroRNA-940 promotes tumor cell invasion and metastasis by downregulating ZNF24 in gastric cancer. Oncotarget. 2015; 6:25418-25428. doi: 10.18632/oncotarget.4456.

62. Gelman IH. Src-family tyrosine kinases as therapeutic targets in advanced cancer. Front Biosci (Elite Ed). 2011; 3:801-807.

63. Wiener JR, Windham TC, Estrella VC, Parikh NU, Thall PF, Deavers MT, Bast RC, Mills GB, Gallick GE. Activated SRC protein tyrosine kinase is overexpressed in late-stage human ovarian cancers. Gynecol Oncol. 2003; 88:73-79.

64. Yuyama K, Sun H, Mitsutake S, Igarashi Y. Sphingolipidmodulated exosome secretion promotes clearance of amyloid-beta by microglia. J Biol Chem. 2012; 287:10977-10989.
65. Kubota S, Chiba M, Watanabe M, Sakamoto M, Watanabe N. Secretion of small/microRNAs including miR-638 into extracellular spaces by sphingomyelin phosphodiesterase 3 . Oncol Rep. 2015; 33:67-73.

66. Guzman N, Agarwal K, Asthagiri D, Yu L, Saji M, Ringel MD, Paulaitis ME. Breast Cancer-Specific miR Signature Unique to Extracellular Vesicles Includes "microRNA-like" tRNA Fragments. Mol Cancer Res. 2015; 13:891-901.

67. Madhavan B, Yue S, Galli U, Rana S, Gross W, Muller M, Giese NA, Kalthoff H, Becker T, Buchler MW, Zoller M. Combined evaluation of a panel of protein and miRNA serum-exosome biomarkers for pancreatic cancer diagnosis increases sensitivity and specificity. Int J Cancer. 2015; 136:2616-2627.

68. Hessvik NP, Sandvig K, Llorente A. Exosomal miRNAs as Biomarkers for Prostate Cancer. Front Genet. 2013; 4:36.

69. Gajos-Michniewicz A, Duechler M, Czyz M. MiRNA in melanoma-derived exosomes. Cancer Lett. 2014; 347:29-37.

70. Lu C, Bonome T, Li Y, Kamat AA, Han LY, Schmandt R, Coleman RL, Gershenson DM, Jaffe RB, Birrer MJ, Sood AK. Gene alterations identified by expression profiling in tumor-associated endothelial cells from invasive ovarian carcinoma. Cancer Res. 2007; 67:1757-1768.

71. Hwang JY, Mangala LS, Fok JY, Lin YG, Merritt WM, Spannuth WA, Nick AM, Fiterman DJ, Vivas-Mejia PE, Deavers MT, Coleman RL, Lopez-Berestein G, Mehta $\mathrm{K}$, et al. Clinical and biological significance of tissue transglutaminase in ovarian carcinoma. Cancer Res. 2008; 68:5849-5858.

72. Aslan B, Monroig P, Hsu MC, Pena GA, Rodriguez-Aguayo C, Gonzalez-Villasana V, Rupaimoole R, Nagaraja AS, Mangala S, Han HD, Yuca E, Wu SY, Ivan C, et al. The ZNF304-integrin axis protects against anoikis in cancer. Nature communications. 2015; 6:7351.

73. Thery C, Amigorena S, Raposo G, Clayton A. Isolation and characterization of exosomes from cell culture supernatants and biological fluids. Curr Protoc Cell Biol. 2006; Chapter 3:Unit 322.

74. Rani S, O'Brien K, Kelleher FC, Corcoran C, Germano $\mathrm{S}$, Radomski MW, Crown J, O'Driscoll L. Isolation of exosomes for subsequent mRNA, MicroRNA, and protein profiling. Methods Mol Biol. 2011; 784:181-195.

75. Wang R, Sun PD. Natural killer cell-mediated shedding of ULBP2. PLoS One. 2014; 9:e91133.

76. Lane RE, Korbie D, Anderson W, Vaidyanathan R, Trau M. Analysis of exosome purification methods using a model liposome system and tunable-resistive pulse sensing. Sci Rep. 2015; 5:7639.

77. Xin H, Li Y, Cui Y, Yang JJ, Zhang ZG, Chopp M. Systemic administration of exosomes released from mesenchymal stromal cells promote functional recovery and 
neurovascular plasticity after stroke in rats. J Cereb Blood Flow Metab. 2013; 33:1711-1715.

78. Landen CN, Jr., Chavez-Reyes A, Bucana C, Schmandt R, Deavers MT, Lopez-Berestein G, Sood AK. Therapeutic EphA2 gene targeting in vivo using neutral liposomal small interfering RNA delivery. Cancer Res. 2005; 65:6910-6918.

79. Gonzalez-Villasana V, Rodriguez-Aguayo C, Arumugam T, Cruz-Monserrate Z, Fuentes-Mattei E, Deng D, Hwang RF,

Wang H, Ivan C, Garza RJ, Cohen E, Gao H, Armaiz-Pena GN, et al. Bisphosphonates inhibit stellate cell activity and enhance antitumor effects of nanoparticle albumin-bound paclitaxel in pancreatic ductal adenocarcinoma. Mol Cancer Ther. 2014; 13:2583-2594.

80. Cvjetkovic A, Lotvall J, Lasser C. The influence of rotor type and centrifugation time on the yield and purity of extracellular vesicles. J Extracell Vesicles. 2014; 3.

81. Paggetti J, Haderk F, Seiffert M, Janji B, Distler U, Ammerlaan W, Kim YJ, Adam J, Lichter P, Solary E, Berchem G, Moussay E. Exosomes released by chronic lymphocytic leukemia cells induce the transition of stromal cells into cancer-associated fibroblasts. Blood. 2015; 126:1106-1117.

82. Eldh M, Lotvall J, Malmhall C, Ekstrom K. Importance of RNA isolation methods for analysis of exosomal RNA: evaluation of different methods. Mol Immunol. 2012; 50:278-286.

83. Gonzalez-Villasana V, Fuentes-Mattei E, Ivan C, Dalton HJ, Rodriguez-Aguayo C, Fernandez-de Thomas RJ, Aslan B, Del CMP, Velazquez-Torres G, Previs RA, Pradeep S, Kahraman N, Wang H, et al. Rac1/Pak1/p38/MMP-2 Axis Regulates Angiogenesis in Ovarian Cancer. Clinical cancer research. 2015; 21:2127-2137.

84. Landen CN, Jr., Lu C, Han LY, Coffman KT, Bruckheimer E, Halder J, Mangala LS, Merritt WM, Lin YG, Gao C, Schmandt R, Kamat AA, Li Y, et al. Efficacy and antivascular effects of EphA2 reduction with an agonistic antibody in ovarian cancer. J Natl Cancer Inst. 2006; 98:1558-1570. 